Atmos. Meas. Tech. Discuss., https://doi.org/10.5194/amt-2017-174

Manuscript under review for journal Atmos. Meas. Tech.

Discussion started: 7 June 2017

(c) Author(s) 2017. CC BY 3.0 License.

\title{
An improved water correction function for Picarro greenhouse gas analyzers
}

\author{
Friedemann Reum ${ }^{1}$, Christoph Gerbig ${ }^{1}$, Jost V. Lavric ${ }^{1}$, Chris W. Rella ${ }^{2}$ and Mathias Göckede ${ }^{1}$ \\ ${ }^{1}$ Max Planck Institute for Biogeochemistry, Jena, Germany \\ $5 \quad{ }^{2}$ Picarro Inc., Santa Clara, CA, USA \\ Correspondence to: Friedemann Reum (freum@bgc-jena.mpg.de)
}

\begin{abstract}
Measurements of dry air mole fractions of atmospheric greenhouse gases are widely used in inverse models of atmospheric tracer transport to quantify the sources and sinks of the gases. The measurements have to be calibrated to a common scale to avoid bias in the inferred fluxes. The World Meteorological Organization (WMO) has set requirements for 10 the inter-laboratory compatibility of atmospheric greenhouse gas measurements to $\pm 0.1 \mathrm{ppm}$ for $\mathrm{CO}_{2}$ (Southern hemisphere $\pm 0.05 \mathrm{ppm}$ ) and to $\pm 2 \mathrm{ppb}$ for $\mathrm{CH}_{4}$. An established series of devices for measurements of greenhouse gas (GHG) mole fractions are the trace gas analyzers manufactured by Picarro, Inc. These have been shown to deliver dry air mole fractions with accuracies within the WMO goals when trace gas signals are measured in wet air and the effects of water vapor are corrected for. Here, we report for the first time on sensitivity of the pressure inside the measurement cavity of Picarro GHG 15 analyzers to water vapor. This sensitivity induces biases in the inferred dry air mole fractions of $\mathrm{CO}_{2}$ and $\mathrm{CH}_{4}$ if they are obtained using the traditional water correction function. To correct for the pressure effect, we add a pressure-related term to the traditional water correction function, and consider differences between the traditional and enhanced water correction function to be biases of the traditional model. The effect primarily affects low water vapor mole fractions from about 0.05 to about $0.5 \%$, a domain that has gone undersampled in previous studies of the water correction for Picarro GHG analyzers. We observed biases up to about $40 \%$ of the WMO tolerances ( $80 \%$ for $\mathrm{CO}_{2}$ in the southern hemisphere). The magnitude of the effect varied across instruments and appeared to be negligible for some, and our experimental results were more robust for $\mathrm{CH}_{4}$ than for $\mathrm{CO}_{2}$. Thus, correction coefficients should be determined for each analyzer individually. Applying our enhanced water correction function improves the accuracy of measurements of dry air mole fractions of $\mathrm{CO}_{2}$ and $\mathrm{CH}_{4}$ in humid air with Picarro GHG analyzers on a scale important for keeping the measurement accuracy within the WMO requirements.
\end{abstract}

\section{Introduction}

Measurements of atmospheric GHG mole fractions are integral data for quantifying the sources and sinks of the gases using inverse models of atmospheric transport (e.g. Kirschke et al., 2013; McGuire et al., 2012). Inverse models require atmospheric measurements calibrated to a common scale, because relative biases in the mole fraction data lead to biases in 
Atmos. Meas. Tech. Discuss., https://doi.org/10.5194/amt-2017-174

Manuscript under review for journal Atmos. Meas. Tech.

Discussion started: 7 June 2017

(c) Author(s) 2017. CC BY 3.0 License.

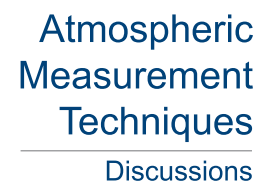

Discussions

the inferred fluxes. The World Meteorological Organization (WMO) has set compatibility goals for atmospheric $\mathrm{CO}_{2}$ and $\mathrm{CH}_{4}$ measurements to $\pm 0.1 \mathrm{ppm}$ for $\mathrm{CO}_{2}\left( \pm 0.05 \mathrm{ppm}\right.$ in the southern hemisphere) and $\pm 2 \mathrm{ppb}$ for $\mathrm{CH}_{4}(\mathrm{WMO}, 2016$ ).

In models of atmospheric greenhouse gas transport, the relevant atmospheric information is the dry air mole fraction, i.e. the number of molecules of the target gas divided by the number of air molecules, not including water vapor. Water vapor is

5 excluded because its large variability would cover any signal in the trace gases. To measure dry air mole fractions in the humid atmosphere, there are two strategies: (i) drying the air before measurement and (ii) measuring the wet air signal and correcting for the effects of water vapor later. There are a variety of techniques to dry sample air, including cooling or streaming it through a nafion membrane dryer. Limitations of this strategy include maintenance requirements, minimum limits to the achievable dryness, and possibly effects of drying on the GHG mole fractions (Rella et al., 2013).

10 GHG analyzers manufactured by Picarro Inc. (Santa Clara, CA), which are based on the cavity ring-down spectroscopy technique (Crosson, 2008), are used at many sites of the international GHG monitoring network because of their signal stability. When using these instruments, the practice is often not to dry the sample air, but instead to measure wet air mole fractions and subsequently correct for the effects of water vapor. Cavity ring-down spectroscopy is based on absorption of laser light by the target gas inside a resonator cavity. Active temperature and pressure control in the cavity are built-in to establish the stable measurement conditions necessary for fitting absorption line shapes. To obtain dry air mole fractions, a water correction function is applied to $\mathrm{CO}_{2}$ and $\mathrm{CH}_{4}$ signals measured in wet air. The established form of the water correction function accounts for the dilution effect of water vapor and its effects on the shapes of the absorption lines (Chen et al., 2010; Rella et al., 2013). Dilution changes the target gas mole fraction linearly, and the effects of line shape changes on the mole fraction measurements are modeled as a second-degree Taylor series. Thus, the overall shape of the traditional water correction function is a parabola (with a dominant linear term and a small quadratic correction), by which measured wet air mole fractions are divided to obtain dry air mole fractions. By using these functions, water vapor effects on $\mathrm{CO}_{2}$ and $\mathrm{CH}_{4}$ can be corrected with residuals below the WMO goals. Better accuracy is achieved by determining individual coefficients for the water correction function specific to each analyzer (Chen et al., 2010; Rella et al., 2013).

Here, we report systematic biases of dry air mole fractions inferred using the traditional parabolic water correction functions that, to our knowledge, have not been investigated yet. In some cases, the observed systematic deviations were as high as about $40 \%$ of the WMO tolerances ( $80 \%$ for $\mathrm{CO}_{2}$ in the southern hemisphere). The largest deviations were at low $\mathrm{H}_{2} \mathrm{O}$ mole fractions around from about 0.05 to about $0.5 \%$. We found that only few measurement points at such low water vapor mole fractions were sampled in previous studies (Chen et al., 2010; Nara et al., 2012; Rella et al., 2013; Winderlich et al., 2010). In this study, we address the systematic deviations introduced by the traditional water correction function, and find that they can be explained by a dependency of the pressure inside the measurement cavity on the water vapor content in the sample air. We present a method to correct for the pressure effect, and quantify the impact this correction has on observations from the field. 
Atmos. Meas. Tech. Discuss., https://doi.org/10.5194/amt-2017-174

Manuscript under review for journal Atmos. Meas. Tech.

Discussion started: 7 June 2017

(c) Author(s) 2017. CC BY 3.0 License.

\section{Atmospheric \\ Measurement Techniques \\ Discussions}

(c) (i)

\section{Methods}

\subsection{Experiments}

To determine the effect of water vapor on $\mathrm{CO}_{2}$ and $\mathrm{CH}_{4}$ measurements, dry air from pressurized gas tanks was humidified and measured with a Picarro GHG analyzer. Pressure in the measurement cavity of the analyzer was monitored with both the

5 built-in internal pressure sensor and an additional external pressure sensor (Fig. 1).

To humidify the air stream, two different methods were used. The first approach was designed to allow stable maintenance of defined levels of the water vapor content. The dry air stream was split into two lines, one of which remained untreated. Air in the other line was directed through a gas washing bottle (glass) containing deionized water (depending on bottle size, about $15 \mathrm{ml}$ to about $500 \mathrm{ml}$ were used in the experiments presented here). Thus, air in this line was saturated with water vapor (mole fraction about $3 \%$ ). Subsequently, the two lines were joined again. The water vapor mole fraction in the rejoined line was controlled by adjusting the flow through the wet and dry lines using needle valves. For one of the experiments (Picarro \#1, see Table 1), instead of using the gas washing bottle approach, air was humidified by mixing air from the gas tank and ambient laboratory air. From this experiment, only pressure data were analyzed.

The second humidification approach was the droplet method. For these experiments, the humidification unit described above was replaced with a tee piece. To humidify the air, a droplet of deionized water $(\sim 1 \mathrm{ml})$ was injected into the line through the tee piece using a syringe. Gradual evaporation of this water droplet then caused a gradient over time from high to low water vapor levels in the sample air.

Pressure inside the measurement cavity of Picarro GHG analyzers is kept stable by a feedback loop between a pressure sensor (General Electric NPC-1210) that is mounted inside the cavity, and the outlet valve of the cavity (inlet valve in socalled Flight-ready Picarro GHG analyzers, which are customized for airborne measurements). With this loop, the cavity pressure is kept stable at 140 Torr. Since Picarro reports cavity pressure in Torr, we will use this unit throughout this paper $(1$ Torr $=133.3224 \mathrm{~Pa})$. In our experiments, pressure in the measurement cavity was monitored with an external pressure sensor (General Electric Druck DPI 142) as well as with the internal sensor. To shield the external sensor from humidity changes, it was installed in a dead end branched from the main line behind a drying cartridge filled with magnesium perchlorate. The pressure measurement line was branched directly upstream of the Picarro GHG analyzer (downstream for Flight-ready analyzers). To match the pressure inside the cavity to within a few Torr, a needle valve was installed as a choke upstream of the pressure measurement branch (downstream for Flight-ready analyzers). This setup allowed us to monitor pressure independently of water vapor content, while the internal pressure sensor still reacted to changes in water vapor levels in the sampling air.

30 The external pressure readings drifted on a timescale relevant for the gas washing bottle experiments. Therefore, in these experiments, dry air was measured between different water vapor levels to calibrate the external pressure readings. Each water vapor level (including dry air) was probed between 15 and 150 minutes (median about 40 minutes) depending on the stability of the external pressure measurement and trace gas readings. For further analysis, average readings from the Picarro 
Atmos. Meas. Tech. Discuss., https://doi.org/10.5194/amt-2017-174

Manuscript under review for journal Atmos. Meas. Tech.

Discussion started: 7 June 2017

(c) Author(s) 2017. CC BY 3.0 License.

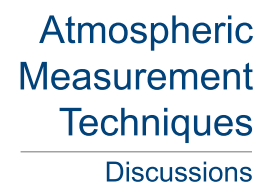

(c) (P)

GHG analyzer and the external pressure sensor of the last 10 minutes of each probing interval were used. Some measurements with low water vapor levels with probing times of only about five minutes from an early experiment (Picarro GHG analyzer \#1, see Table 1) were included as well. The order of water vapor levels was altered between experiments, including varying from wet to dry, dry to wet, and random switches between dryer and wetter air.

5 Experiments were performed with five Picarro GHG analyzers (Table 1).

\subsection{Traditional parabolic water correction function}

The effect of water on trace gas measurements made using Picarro GHG analyzers can be described by a water correction function $f_{c}(h)$, where $c$ denotes the target gas (here: $\mathrm{CO}_{2}$ or $\mathrm{CH}_{4}$ ) and $h$ is the water vapor mole fraction (measured by the Picarro analyzer). The analyzer measures the wet air mole fraction $c_{w e t}(h)$, which is related to the dry air mole fraction $c_{d r y}$ 10 by the water correction function:

$c_{d r y}=\frac{c_{w e t}(\boldsymbol{h})}{f_{c}(\boldsymbol{h})}$

The traditional form of the water correction function takes into account dilution and line shape effects (details in Sect. 1). These are described by a second-degree Taylor series, i.e. a parabola:

$f_{c}(h)=1+a_{c} \cdot h+b_{c} \cdot h^{2}$

The coefficients $a_{c}$ and $b_{c}$ can be derived from water correction experiments such as those described in Sect. 2.1.

\section{Results}

$15 \quad 3.1 \quad$ Links among external pressure measurement, $\mathrm{CO}_{2}, \mathrm{CH}_{4}, \mathrm{H}_{2} \mathrm{O}$ and cavity pressure

To establish the link among the external pressure measurement, $\mathrm{CO}_{2}, \mathrm{CH}_{4}$, and internal cavity pressure for each Picarro GHG analyzer, the cavity pressure was varied manually using Picarro Inc. software in the range observed when varying water vapor content. Externally measured pressure, $\mathrm{CO}_{2}$, and $\mathrm{CH}_{4}$ varied linearly with internally monitored cavity pressure, with similar slopes for all instruments. As an example, the values for Picarro \#3 obtained in dry air are shown in Table 2.

20 The water vapor measurement was not sensitive to cavity pressure. The slopes in wet air $\left(3 \% \mathrm{H}_{2} \mathrm{O}\right)$ were measured for Picarro $\# 3$ and were very similar to the slopes in dry air $\left(\mathrm{CO}_{2}:+5 \%, \mathrm{CH}_{4}:-2 \%\right.$, cavity pressure: $\left.+1 \%\right)$. Hence, internal cavity pressure, $\mathrm{CO}_{2}$ and $\mathrm{CH}_{4}$ were modeled as linear functions of externally measured pressure for subsequent analyses.

\subsection{Dependency of cavity pressure on water vapor content}

We monitored cavity pressure using an external sensor during gas washing bottle experiments (Sect. 2.1) for three different

25 Picarro GHG analyzers (Table 1). The pressure readings of the internal pressure sensors were, as expected, stable at 140 Torr with standard deviations of 0.015 Torr or less. To calculate a "corrected cavity pressure" from the external pressure 
Atmos. Meas. Tech. Discuss., https://doi.org/10.5194/amt-2017-174

Manuscript under review for journal Atmos. Meas. Tech.

Discussion started: 7 June 2017

(c) Author(s) 2017. CC BY 3.0 License.

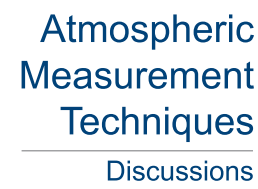

Discussions

measurement, pressure readings for dry air before and after each wet air measurement were interpolated to the times of the wet air measurements. The deviations between the wet air pressure values and the interpolated dry air pressure values were multiplied with the slope described in Sect. 3.1, and added to the dry air cavity pressure of 140 Torr. The corrected cavity pressure obtained in this way varied systematically with the water vapor mole fraction of the sample air (Fig. 2). The

5 variations displayed a uniform pattern for all three instruments. The pressure dropped in the presence of water vapor, and the gradient of pressure with respect to water vapor was larger between 0 and about $0.2 \% \mathrm{H}_{2} \mathrm{O}$ than for higher water vapor content, exhibiting a "bend" where the two regimes meet. The deviations were up to 0.5 Torr for $3 \% \mathrm{H}_{2} \mathrm{O}$.

We describe the relationship between cavity pressure and water vapor mole fraction with an empirical function:

$p(h)=p_{0}+s \cdot h+d_{p} \cdot\left(e^{-\frac{h}{h_{p}}}-1\right)$

10

In this equation, $p$ is the cavity pressure as determined from the external pressure measurement, $h$ is the water vapor mole fraction, $h_{p}$ is the position of the pressure bend described above, $d_{p}$ is a measure for the pressure gradient at $0 \%<h<h_{p}$, $p_{0}$ is the pressure in dry air (fixed at 140 Torr), and $s$ is the slope for $h \gg h_{p}$. Note that this empirical fit function is valid only in the water vapor range covered by measurements (see Fig. 2). Data from droplet experiments suggest that the pressure variation does not continue linearly along the slopes derived here at higher water vapor levels, so an extrapolation is not recommended.

All free parameters of the pressure model $\left(s, d_{p}\right.$ and $\left.h_{p}\right)$ varied between instruments (Table 3$)$. For the empirical water correction functions for $\mathrm{CO}_{2}$ and $\mathrm{CH}_{4}$, only the pressure bend position $\left(h_{p}\right)$ is relevant, as will be shown later. The mean estimate of $h_{p}$ from all three experiments was (mean and standard deviation):

20

$h_{p}=(0.079 \pm 0.014) \% H_{2} O$

\subsection{Correction of the pressure effect on $\mathrm{CO}_{2}$ and $\mathrm{CH}_{4}$}

Reliable data for both pressure and the target gases $\mathrm{CO}_{2}$ and $\mathrm{CH}_{4}$ were obtained in one experiment (with Picarro \#3), which is presented in this section. Based on the data, four models were tested as potential water correction functions for $\mathrm{CO}_{2}$ and $\mathrm{CH}_{4}$ to examine performance, robustness, transferability, and consistency of the results. Model (i) was the traditional parabolic function, Eq. (2). The other three models represent different strategies to correct for the pressure effect. Model (ii) consisted of first correcting the pressure effect on the wet air mole fractions by estimating the pressure bias from Eq. (3) and then correcting the trace gas bias using the sensitivity of $\mathrm{CO}_{2}$ and $\mathrm{CH}_{4}$ to pressure (Table 2); then the traditional parabolic water correction was applied to the corrected wet air mole fractions. For models (iii) and (iv), the traditional parabolic model was expanded to account for the pressure effect. Since the trace gas readings of the analyzer varied linearly with pressure 
Atmos. Meas. Tech. Discuss., https://doi.org/10.5194/amt-2017-174

Manuscript under review for journal Atmos. Meas. Tech.

Discussion started: 7 June 2017

(c) Author(s) 2017. CC BY 3.0 License.

\section{Atmospheric \\ Measurement \\ Techniques \\ Discussions}

(c) (P)

(Sect. 3.1), the pressure effect was described as in Eq. (2), i.e. as a linear and a non-linear term. Since a linear dependency is already accounted for in the traditional parabolic model, the non-linear part of Eq. (2) was added to Eq. (3) to obtain a new model for the water correction:

$f_{c}^{p}(\boldsymbol{h})=\underbrace{\mathbf{1}+\boldsymbol{a}_{c} \cdot \boldsymbol{h}+\boldsymbol{b}_{c} \cdot \boldsymbol{h}^{2}}_{f_{c}(\boldsymbol{h})}+\boldsymbol{d}_{c} \cdot\left(\boldsymbol{e}^{-\frac{h}{h_{p}}}-\mathbf{1}\right)$

The parameter $d_{c}$ describes the magnitude of the pressure change at low water vapor contents and sensitivity of the target

5 gas to the pressure change. The parameter $h_{p}$ is the pressure bend position from Eq. (3). In model (iii), the parameters $a_{c}, b_{c}$, $d_{c}$ and $h_{p}$ from Eq. (5) were fitted to the trace gas data. Model (iv) was the same as model (iii) except that the pressure bend position $h_{p}$ was set to the value obtained from the pressure data. Since all free parameters in model (iii) were estimated from the available trace gas data, this model was the most consistent with the data. Therefore, in subsequent analyses, we assumed that the fit to model (iii) yielded the true water correction function. Hence, we used the differences between the results from this model and the others as estimates of their biases.

The experiment was performed with dry air mole fractions of $404.0 \mathrm{ppm} \mathrm{CO}_{2}$ and $1842 \mathrm{ppb} \mathrm{CH}_{4}$. Water-corrected $\mathrm{CO}_{2}$ and $\mathrm{CH}_{4}$ data from this experiment are shown in Fig. 3. For $\mathrm{CH}_{4}$, the most striking visible feature was the wave-like structure in the dry air mole fractions when using model (i), the traditional parabolic water correction function. The maximum negative bias of this model was $0.85 \mathrm{ppb}$ at $0.17 \% \mathrm{H}_{2} \mathrm{O}$ (corresponding to $0.046 \%$ of the dry air mole fraction), and the maximum positive bias was $0.37 \mathrm{ppb}$ at $1.7 \% \mathrm{H}_{2} \mathrm{O}$. Hence, the peak-to-peak difference was $1.2 \mathrm{ppb}$. The standard deviation of the dry air mole fractions estimated with this model was $0.35 \mathrm{ppb}$. By contrast, no structure was visible in the dry air mole fractions calculated with any of the three formulations taking into account the pressure change. This is reflected in the lower standard deviations of the dry air mole fractions, which were $0.20 \mathrm{ppb}$ for model (ii), $0.17 \mathrm{ppb}$ for model (iii) and $0.18 \mathrm{ppb}$ for model (iv). This demonstrates the improvement achieved by correcting for the effect of pressure bias on $\mathrm{CH}_{4}$.

20 The result from model (ii) yielded slightly larger deviations from the mean than models (iii) and (iv) in the range $0.1-0.3 \%$ $\mathrm{H}_{2} \mathrm{O}$. These deviations were compatible with a sensitivity of $\mathrm{CH}_{4}$ to cavity pressure changes of $80 \%$ of the value inferred in Sect. 3.1, since at this value the results from model (ii) resemble the results from model (iv). This discrepancy is discussed in Sect. 4.3.

The pressure bend position estimated from the $\mathrm{CH}_{4}$ data was $h_{p}=(0.059 \pm 0.015) \% \mathrm{H}_{2} \mathrm{O}$. This is smaller than the estimate based on pressure data of $h_{p}=(0.095 \pm 0.011) \% \mathrm{H}_{2} \mathrm{O}$. Despite this discrepancy, the two models yielded very similar dry air mole fractions, with differences within $0.12 \mathrm{ppb}$ and a peak-to-peak difference of $0.22 \mathrm{ppb}$ between 0.05 and $0.39 \% \mathrm{H}_{2} \mathrm{O}$. This demonstrates the robustness of the method against uncertainties in $h_{p}$.

The wave-like structure seen in the $\mathrm{CH}_{4}$ dry air mole fractions estimated using the traditional parabolic water correction function was absent in the $\mathrm{CO}_{2}$ data for this instrument. The standard deviations of the dry air mole fractions were similar for all models (model (i): 0.017 ppm, model (ii): $0.021 \mathrm{ppm}$, models (iii) and (iv): $0.014 \mathrm{ppm}$ ). 
Atmos. Meas. Tech. Discuss., https://doi.org/10.5194/amt-2017-174

Manuscript under review for journal Atmos. Meas. Tech.

Discussion started: 7 June 2017

(c) Author(s) 2017. CC BY 3.0 License.

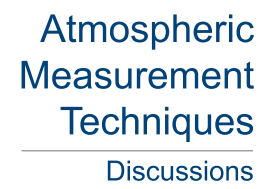

Atmospheric

Techniques

Discussions

Using model (ii) induced a bias similar to the one present in the results of model (i) for $\mathrm{CH}_{4}$ but with opposite sign (Fig. 3). This hints at an overcompensation of the pressure effect on $\mathrm{CO}_{2}$. Indeed, following the same argument as for $\mathrm{CH}_{4}$, the results of model (iv) were reproduced when the sensitivity of $\mathrm{CO}_{2}$ to cavity pressure changes was set to $35 \%$ of the value presented in Table 2. Note that the wave-like structure in $\mathrm{CO}_{2}$ was apparent for one other instrument (Picarro \#5, see Sect. 3.4 and

5 3.5.1). This has not been presented in this section since no external pressure sensor data were obtained for this instrument.

\subsection{Consistency across instruments}

To investigate whether common coefficients applicable to all Picarro GHG analyzers can be given for the enhanced water correction function, we performed water correction experiments with several Picarro GHG analyzers. Although reliable pressure and trace gas data from a single experiment were obtained for only one instrument (presented in Sect. 3.3), trace gas data from water correction experiments were obtained for two more analyzers. The pressure effect on the trace gas data from these instruments differed in magnitude. Out of the three instruments for which trace gas data were investigated (Picarros \#3, $\# 4$, and \#5), two exhibited the pressure effect visibly for $\mathrm{CH}_{4}$ (Fig. 3 and Fig. 5; the exception was Picarro \#4, see Fig. 4). In contrast, the $\mathrm{CO}_{2}$ measurements of two instruments (\#3 and \#4) seemed to be unaffected by pressure changes (Fig. 3 and Fig. 4; the exception was Picarro \#5, see Fig. 5). The differences make clear that common coefficients applicable to all Picarro GHG analyzers can not be given based on our data. This is further discussed in Sect. 4.3 and Sect. 4.4.

\subsection{Application to ambient measurements}

In this section, we demonstrate the impact that the pressure effect has on ambient GHG observations from a site in northeast Siberia. The site is located in the remote village of Ambarchik on the coast of the Arctic Ocean $\left(69.62^{\circ} \mathrm{N}, 162.30^{\circ} \mathrm{E}\right)$, and has been operational since August 2014. Air inlets are at $27 \mathrm{~m}$ and $14 \mathrm{~m}$ above ground level, and probed in turns for intervals of 15 and 5 minutes, respectively. The gases $\mathrm{CO}_{2}$ and $\mathrm{CH}_{4}$ are measured in the humid air stream with a Picarro G2301 analyzer (Picarro \#5). The measurements are calibrated automatically by measuring gas tanks calibrated to the WMO scales $\mathrm{X} 2007\left(\mathrm{CO}_{2}\right)$ and X2004A $\left(\mathrm{CH}_{4}\right)$ every 116 hours.

\subsubsection{Deriving coefficients for the improved water correction function without pressure data}

In this section, we derive coefficients for the improved water correction function, Eq. (5), for $\mathrm{CO}_{2}$ and $\mathrm{CH}_{4}$ for the Picarro G2301 analyzer operated in Ambarchik. For this instrument, one water correction experiment with the gas washing bottle method (see Sect. 2.1) was performed, using dry air from a pressurized tank with mole fractions of $352.9 \mathrm{ppm} \mathrm{CO}_{2}$ and 1797 ppb $\mathrm{CH}_{4}$. Cavity pressure was not monitored during this experiment. We estimated the parameters $a_{c}, b_{c}$ and $d_{c}$ from the trace gas data (Table 4 and Table 5), but the number of data points was insufficient to also estimate the pressure bend position $h_{p}$. Therefore, we used the mean $h_{p}$ from the three experiments with external pressure monitoring, Eq. (4), and investigated the uncertainty associated with this procedure. 
Atmos. Meas. Tech. Discuss., https://doi.org/10.5194/amt-2017-174

\section{Atmospheric

Manuscript under review for journal Atmos. Meas. Tech.

Discussion started: 7 June 2017

(c) Author(s) 2017. CC BY 3.0 License.

As a conservative estimate, we considered an interval of three standard deviations around the mean a plausible range for $h_{p}$, i.e. $h_{p} \in[0.036,0.122] \% \mathrm{H}_{2} \mathrm{O}$. Varying $h_{p}$ in small steps within this interval, we fitted the other parameters of Eq. (5) to the trace gas data. To assess the uncertainty associated to using the mean $h_{p}$, we assumed that one of the $h_{p}$ yielded the true water correction function for this instrument, and determined whether using the mean $h_{p}$ could induce a larger error than

5 using the traditional parabolic correction. For this assessment, we compared not only the data points obtained during the experiment, but sampled the fitted functions at 999 evenly spaced points over the range of $\mathrm{H}_{2} \mathrm{O}$ covered during the experiment. For $\mathrm{CO}_{2}$, the maximum deviation between the function using the mean $h_{p}$ and any other $h_{p}$ in the plausible range was $0.007 \mathrm{ppm}$, while the best result for the maximum deviation between the traditional parabolic correction and the improved functions with $h_{p}$ in the plausible range was $0.017 \mathrm{ppm}$. For $\mathrm{CH}_{4}$, the deviations were $0.20 \mathrm{ppb}$ and $0.35 \mathrm{ppb}$, respectively. Therefore, maximum bias due to the uncertainty of $h_{p}$ was smaller than the minimum bias when using the traditional parabolic correction for both $\mathrm{CO}_{2}$ and $\mathrm{CH}_{4}$.

For reference, we also investigated the values for $h_{p}$ estimated from the trace gas data. Fitting Eq. (5) to $\mathrm{CH}_{4}$ yielded $h_{p}=(0.086 \pm 0.053) \% \mathrm{H}_{2} \mathrm{O}$, close to the mean $h_{p}$ from the three pressure experiments but with a large uncertainty. For $\mathrm{CO}_{2}$, the fit yielded $h_{p}=(0.34 \pm 0.19) \% \mathrm{H}_{2} \mathrm{O}$, outside of the range considered plausible for $h_{p}$ and again with a very large

15 uncertainty. It may be argued that the plausible range $h_{p}$ should be extended to $0.34 \% \mathrm{H}_{2} \mathrm{O}$. Using this extended range, the argument for the benefit of the improved water correction over the traditional one despite the uncertainty of $h_{p}$ was weaker, but still held. However, we argue that the estimate $h_{p}=0.34 \% \mathrm{H}_{2} \mathrm{O}$ is probably far from the true pressure bend position for this instrument. First, the estimate was based on $\mathrm{CO}_{2}$ data, which were less consistent with pressure data than $\mathrm{CH}_{4}$ data for another instrument (Sect. 3.3). Second, it is far from the pressure bend positions of all three instruments for which pressure data were obtained (Sect. 3.2). Third, the estimate was based on very few data points and was not robust against jackknife resampling (not shown). For these reasons, we consider $h_{p}$ from Eq. (4) to be a realistic estimate for this Picarro analyzer.

To assess the bias of the traditional parabolic fit function, we assumed that the fit with pressure correction term using the

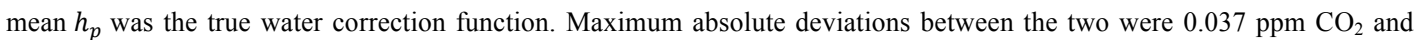

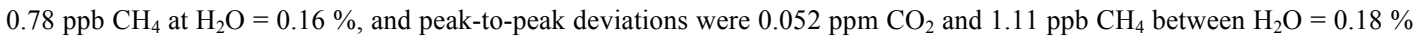
and $1.8 \%$. These deviations corresponded to biases of $0.0104 \% \mathrm{CO}_{2}$ and $0.0437 \% \mathrm{CH}_{4}$. As an example, for dry air mole fractions of $400 \mathrm{ppm} \mathrm{CO}_{2}$ and $2000 \mathrm{ppb} \mathrm{CH}_{4}$, the maximum absolute bias of the traditional water correction function would be $0.042 \mathrm{ppm} \mathrm{CO}_{2}$ and $0.87 \mathrm{ppb} \mathrm{CH}_{4}$.

In Sect. 3.3, we compared the sensitivities of $\mathrm{CO}_{2}$ and $\mathrm{CH}_{4}$ to cavity pressure inferred from controlled cavity pressure changes with those inferred from water vapor changes for Picarro \#3. We made the same comparison for Picarro \#5 under the assumptions that the cavity pressure dependency on water vapor and the sensitivities of the trace gases to controlled cavity pressure changes were the same as for Picarro \#3. The data from the water correction experiment were compatible with a sensitivity of $\mathrm{CO}_{2}$ to cavity pressure change of $60 \%$ of the value from controlled cavity pressure changes, which was 
Atmos. Meas. Tech. Discuss., https://doi.org/10.5194/amt-2017-174

Manuscript under review for journal Atmos. Meas. Tech.

Discussion started: 7 June 2017

(c) Author(s) 2017. CC BY 3.0 License.

\section{Atmospheric \\ Measurement \\ Techniques \\ Discussions}

higher than the $35 \%$ for Picarro \#3. The corresponding number for $\mathrm{CH}_{4}$ was $70 \%$, which more closely matched the $80 \%$ of Picarro \#3.

\subsubsection{Impact of the improved water correction}

In this section, we describe the impact of the improved water correction on hourly averages of $\mathrm{CO}_{2}$ and $\mathrm{CH}_{4}$ data from

5 Ambarchik over the years 2015 and 2016.

Differences between the traditional and improved water correction had a seasonal cycle following the seasonal cycle of water vapor content in the sample air (Fig. 6). Maximum water vapor mole fractions occurred in July and August, when they averaged around $(0.9 \pm 0.2) \%$. This was close to the water vapor content where the bias of the traditional parabolic water corrections changed sign (Fig. 5). Hence, the summer biases averaged (0.00 \pm 0.01$) \mathrm{ppm} \mathrm{CO}_{2}$ and $(0.0 \pm 0.2) \mathrm{ppb}^{\mathrm{CH}_{4}}$,

10 and were thus negligible. In winter, the water vapor content was in the range of the pressure bend position, where the bias

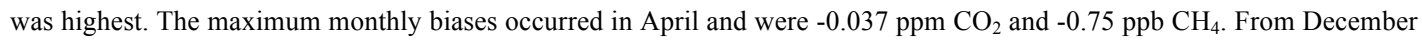
to March, water vapor content episodically dropped well below the pressure bend position (this occurred when the air temperature dropped below about $-25^{\circ} \mathrm{C}$ ), thus the bias decreased. During the coldest temperatures, which occurred in February, the biases were $-0.02 \mathrm{ppm} \mathrm{CO}_{2}$ and $-0.5 \mathrm{ppb} \mathrm{CH}_{4}$

15 We also investigated the effect of the improved water correction on dry air calibrations at this site (data not shown). Calibrations were performed with calibrated dry air gas tanks periodically. The measurement system was flushed with dry air for at least 13 minutes before data were used. This left so little water vapor in the system that the remaining effects were negligible.

\subsection{Evaluation of droplet experiments for the improved water correction}

20 Droplet experiments are a quick and simple method to obtain data for correcting the influence of water vapor on a Picarro GHG analyzer (Rella et al., 2013). We performed a series of droplet experiments (details on the setup are given in Sect. 2.1) with Picarro \#1, and derived coefficients for the improved water correction function, Eq. (5), for $\mathrm{CO}_{2}$ and $\mathrm{CH}_{4}$. We used data below $3.5 \% \mathrm{H}_{2} \mathrm{O}$ and where the difference between subsequent $\mathrm{H}_{2} \mathrm{O}$ measurements was less than $0.005 \%$. The latter was an empirical filter to exclude the fastest water vapor variations while leaving enough data for fitting. The temporal variation of water vapor during these experiments was fastest during evaporation of the last bits of the droplets, i.e. during the transition from about $0.5-1 \%$ to $0 \% \mathrm{H}_{2} \mathrm{O}$ (Fig. 7). As determined in the gas washing bottle experiments, this was the domain of fastest pressure variations, and the pressure during these experiments was consistently too low in this domain, with large variations between the experiments (Fig. 8). We discuss this deviation in Sect. 4.5.

Consequently, differences between water correction fits were expected. Indeed, the differences between the fit functions for the different droplets were extremely large around the pressure bend position $\left(0.17 \mathrm{ppm} \mathrm{CO}_{2}\right.$ between droplets 2 and 4 at $0.29 \% \mathrm{H}_{2} \mathrm{O}$ and $6.0 \mathrm{ppb} \mathrm{CH}_{4}$ between droplets 1 and 2 at $0.18 \% \mathrm{H}_{2} \mathrm{O}$; Fig. 9). When fixing the pressure bend position to the value from the gas washing bottle experiment for this instrument $\left(h_{p}=0.066 \% \mathrm{H}_{2} \mathrm{O}\right)$, the scatter increased to $0.24 \mathrm{ppm}$ 
Atmos. Meas. Tech. Discuss., https://doi.org/10.5194/amt-2017-174

Manuscript under review for journal Atmos. Meas. Tech.

Discussion started: 7 June 2017

(c) Author(s) 2017. CC BY 3.0 License.

\section{Atmospheric \\ Measurement \\ Techniques \\ Discussions}

(c) (†)

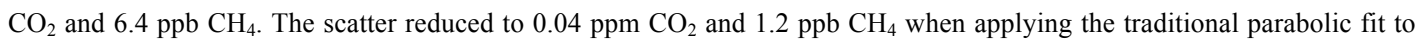
these data, which illustrates that the experiments were consistent apart from the final drop of the water vapor mole fraction to $0 \% \mathrm{H}_{2} \mathrm{O}$, where the pressure changed most rapidly.

\section{Discussion}

\section{4.1 Dependency of cavity pressure on water vapor content}

Our results demonstrate that the cavity pressure of Picarro GHG analyzers is sensitive to the water vapor content of the measured air. This effect influences the dependency of $\mathrm{CO}_{2}$ and $\mathrm{CH}_{4}$ on water vapor.

\subsubsection{Possible underlying effect}

We speculate that the observed sensitivity of internal pressure readings to humidity levels in the sampling air is due to

10 adsorption of $\mathrm{H}_{2} \mathrm{O}$ molecules on the pressure sensor inside the cavity. This sensor controls the outlet valve of the cavity (inlet valve for Flight-ready analyzers) to keep the cavity pressure stable. The pressure measurement is based on a piezoresistive strain gauge exposed to the pressure media (air in the cavity). The strain gauge is mounted on a thin diaphragm, which is deflected by air pressure. The resulting strain causes a change in electrical resistance and creates an output voltage varying with pressure. Water molecules adsorbed on the strain gauge, diaphragm, or adjacent parts of the sensor may change its

15 response to pressure mechanically, and/or may affect the electrical properties of the circuit. If either or both were the case, the deviating pressure readings during droplet experiments could be due to an equilibration time of the adsorption process. Indeed, the largest pressure deviations were observed when the water content changed fastest (Fig. 7 and Fig. 8). However, elucidating the underlying physical effect of the pressure changes is beyond the scope of this paper, and was not investigated further.

\subsubsection{Uncertainties of the external pressure measurement}

The sensitivities of the external pressure measurement to cavity pressure were derived by manually varying cavity pressure (Sect. 3.1). It is possible that the relationships do not hold for variations of water vapor. One potential influence is the drying agent in the line of the external pressure sensor, which may affect the sensor readings due to the differences in partial pressure of water vapor. Additionally, the flow through the needle valves used as chokes to match the external pressure to cavity pressure may be sensitive to water vapor.

To investigate these possible effects, we measured the sensitivity of the external pressure measurement to cavity pressure in dry and wet air $\left(3 \% \mathrm{H}_{2} \mathrm{O}\right)$ for Picarro \#3, and found no difference (Sect. 3.1). This indicates that cavity pressure is indeed well-represented by the external pressure measurement in equilibrium.

Note that, for the empirical correction of the pressure effect on $\mathrm{CO}_{2}$ and $\mathrm{CH}_{4}$, pressure data were used only if the data obtained in a water correction experiment were insufficient to constrain all parameters of the improved water correction 
Atmos. Meas. Tech. Discuss., https://doi.org/10.5194/amt-2017-174

Manuscript under review for journal Atmos. Meas. Tech.

Discussion started: 7 June 2017

(c) Author(s) 2017. CC BY 3.0 License.

\section{Atmospheric \\ Measurement \\ Techniques \\ Discussions}

(c) (P)

function (Sect. 3.5.1). As long as sufficient data are available, uncertainties in our pressure data are of no importance for the empirical water correction.

\subsection{Improvement over traditional parabolic water correction function}

As described in Sect. 3.1, $\mathrm{CO}_{2}$ and $\mathrm{CH}_{4}$ depend linearly on pressure. Consequently, the pressure bend (Fig. 2) is featured in

5 the trace gas data as well. This behavior cannot be modeled with the traditional parabolic water correction function, and hence causes biases in dry air mole fractions derived with the traditional correction. For some instruments, the pressure bend was visible as water-dependent bias when using parabolas as water correction functions (Fig. 3 and Fig. 5). The improved water correction function, Eq. (5), resulted in residuals without systematic structure. The bias observed between the traditional and improved water correction functions was up to $0.037 \mathrm{ppm} \mathrm{CO}_{2}$ (Picarro \#5, dry air mole fraction $352.9 \mathrm{ppm}$ )

10 and $0.85 \mathrm{ppb} \mathrm{CH}_{4}$ (Picarro \#3, dry air mole fraction $1842 \mathrm{ppb}$ ), with peak-to-peak differences of up to $0.052 \mathrm{ppm} \mathrm{CO}_{2}$ and $1.2 \mathrm{ppb} \mathrm{CH}_{4}$, which can appear in ambient air measurements as seasonal cycles or as differences between sites depending on humidity differences.

To derive water correction coefficients for an instrument, enough data must be available to constrain at least the sensitivity of $\mathrm{CO}_{2}$ and $\mathrm{CH}_{4}$ to the pressure effect. If not enough data are available to constrain the pressure bend position, it may be possible to use the mean value from our experiments, $h_{p}=(0.079 \pm 0.014) \% \mathrm{H}_{2} \mathrm{O}$. If this is attempted, one must investigate whether the uncertainty in the pressure bend position may introduce a larger bias than the traditional water correction function (Sect. 3.5.1).

\subsection{Inconsistencies between trace gas- and pressure data}

In Sect. 3.3, we found that correcting for the pressure effect on $\mathrm{CO}_{2}$ and $\mathrm{CH}_{4}$ by using the pressure bias and the sensitivities of the trace gas measurements to cavity pressure during controlled pressure changes (model (ii)) overcompensates the pressure effect. There are two possible explanations: (1) the external pressure measurement may have overestimated the changes in cavity pressure, or (2) the trace gas mole fractions delivered to the analyzer varied systematically with water vapor. If explanation (1) were true, the sensitivity of the external pressure sensor reading to controlled cavity pressure changes (Sect. 3.1) would have been different than to changes due to water vapor. There is no evidence for such an effect (Sect. 4.1.2). Furthermore, $\mathrm{CO}_{2}$ and $\mathrm{CH}_{4}$ would have been affected in the same way, which was not the case, which makes this hypothesis unlikely. Explanation (2) seems more likely, since overall $\mathrm{CO}_{2}$ results were less robust than those for $\mathrm{CH}_{4}$. We observed no visible pressure effect at all on $\mathrm{CO}_{2}$ from two out of three instruments (Fig. 3 and Fig. 4). In one of these instruments (\#3), the pressure effect was seen in $\mathrm{CH}_{4}$ in the same experiment (Fig. 3). The fact that $\mathrm{CO}_{2}$ and $\mathrm{CH}_{4}$ behaved differently suggests that the inconsistent results for $\mathrm{CO}_{2}$ were due to the variations in the mole fraction delivered to the Picarro analyzer. A difference between the two gases is the higher solubility of $\mathrm{CO}_{2}$ in water, which makes it difficult to deliver a constant $\mathrm{CO}_{2}$ mole fraction to the analyzer under varying humidity. However, we carefully observed the equilibration of trace gas mole fractions during the experiments. It is possible that an equilibration effect was at play at a 
Atmos. Meas. Tech. Discuss., https://doi.org/10.5194/amt-2017-174

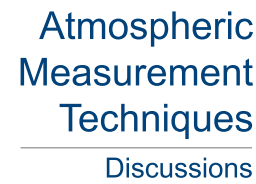

Manuscript under review for journal Atmos. Meas. Tech.

Discussion started: 7 June 2017

(c) Author(s) 2017. CC BY 3.0 License.

Discussions

(c) $($ P)

time scale much longer than an hour, since this may have gone unobserved in our experiments. If this explanation were true, the systematic difference between dry air and wet air trace gas mole fractions would have precisely compensated for the pressure bend, which seems unlikely.

Thus, the reason for the poor performance of model (ii) in Sect. 3.3, and the apparent absence of the effect especially on $\mathrm{CO}_{2}$

5 in some cases remains unclear. We recommend not using model (ii), and instead deriving all coefficients from the trace gas data. This implies that, to correct for the pressure effect, no external pressure measurement is necessary. We also recommend considering using the pressure bend position derived from $\mathrm{CH}_{4}$ data for $\mathrm{CO}_{2}$ in case of discrepancies, because the $\mathrm{CH}_{4}$ data appeared more consistent with the pressure data in our experiments.

\subsection{Transferability of the correction function to other instruments}

10 The form of the pressure dependency on water vapor was the same for all instruments tested. The magnitude of the effect on $\mathrm{CO}_{2}$ and $\mathrm{CH}_{4}$ differed across instruments. In some cases, the effect on $\mathrm{CO}_{2}$ (two out of three instruments) and $\mathrm{CH}_{4}$ (one of these two instruments) even appeared negligible. In those cases, it may be possible that a small effect exists but is masked by random fluctuations. Therefore, correction coefficients for the water correction have to be obtained for each Picarro GHG analyzer individually.

\subsection{Effect on dry air calibrations}

The fact that the pressure effect is largest in almost dry air and our experience with equilibration effects during droplet experiments led us to investigate whether the pressure effect is relevant for calibration measurements with dry air. At the Ambarchik site, very little water vapor was left during dry air calibrations, and the improved water correction had a negligible effect on the calibrations. However, the improvement may be relevant when residual water levels are higher. When switching from humid ambient air to a dry air gas tank, cavity pressure changes quickly. Hence, pressure equilibration may influence the trace gas data despite low residual water levels similarly as we observed during droplet experiments. This highlights the need to allow time for pressure equilibration during calibration measurements using dry air (see Sect. 4.6 about the calibration time).

\subsection{Droplet experiments}

25 We attempted to correct the pressure effect using data from droplet experiments and found inconsistent results (Sect. 3.6). The key difference between droplet experiments and gas washing bottle experiments is the temporal variation of water vapor in the air stream. During gas washing bottle experiments, the median probing time of a water vapor level was 40 minutes. After this time, the pressure- and trace gas readings all appeared to be in equilibrium. This included the external pressure reading, which may have had longer equilibration times than cavity pressure. The temporal variation of water vapor content

30 during droplet experiments was somewhat random, but in general, the droplets dried up very quickly after sustaining a level of about 0.5 to $1 \% \mathrm{H}_{2} \mathrm{O}$ for several minutes. Since this behavior matched our previous experiences with the droplet method 
Atmos. Meas. Tech. Discuss., https://doi.org/10.5194/amt-2017-174

Manuscript under review for journal Atmos. Meas. Tech.

Discussion started: 7 June 2017

(c) Author(s) 2017. CC BY 3.0 License.

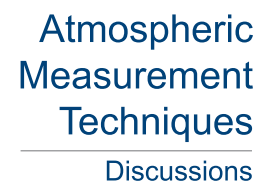

Atmospheric

Techniques

Discussions

(c) (i)

(not shown), we generalize the implications. The fast drop to $0 \% \mathrm{H}_{2} \mathrm{O}$ has two implications for the correction of the pressure bend: (i) few data are available for fitting, and (ii) there is not enough time for the internal pressure sensor to equilibrate, which means it will always be influenced by the water vapor content during at least the last few minutes. Since the water vapor content generally decreases over time in droplet experiments, the pressure readings during fast water vapor variations

5 will in most cases be too low, especially during the fast drop to $0 \% \mathrm{H}_{2} \mathrm{O}$. This pattern is demonstrated in Fig. 8, which also shows that cavity pressure was closest to equilibrium during the droplet experiment with the slowest $\mathrm{H}_{2} \mathrm{O}$ variation before the droplet dried up. Since we have no reliable $\mathrm{CO}_{2}$ and $\mathrm{CH}_{4}$ data from a gas washing bottle experiment for this instrument, we could not make a direct comparison of the water correction functions obtained using droplets and using the gas washing bottle method. However, since the pressure deviation was systematic, we argue that the pressure effect is in general 10 exaggerated by droplet data. The large scatter between the water correction functions based on the different droplets is illustrated in Fig. 9, highlighting that this method does not provide stable-enough signals to derive coefficients for the improved water correction function.

\subsection{Impact of the improved water correction function on inversions of atmospheric transport}

We observed biases persistent over several weeks of around $40 \%$ of the WMO goals $\left(80 \%\right.$ for $\mathrm{CO}_{2}$ in the southern hemisphere) in field data when we applied the traditional parabolic water correction (Sect. 4.2).

Several studies have assessed the impact of observation bias on retrieved fluxes for $\mathrm{CO}_{2}$ (Masarie et al., 2011; Peters et al., 2010; Rödenbeck et al., 2006). The results indicated small impacts of observation biases considerably larger than the WMO goals on annual flux budgets at continental scales. The flux results were more sensitive to model errors such as imperfect atmospheric transport and coarse resolution of the transport and flux model, and differences in the prior flux fields. This suggests that the biases of the traditional water correction function probably only have a small impact on retrieved fluxes. However, the observation bias scenarios in these studies were different then the patterns expected from the traditional water correction. For instance, a bias with a seasonal cycle has not been investigated. In most scenarios, only few stations out of the whole station network used for optimizing fluxes were assigned a bias (Masarie et al., 2011; Rödenbeck et al., 2006), whereas Picarro GHG analyzers are widely used, so that larger parts of station networks can be affected. Furthermore, there may be larger impacts at smaller spatial scales. Despite the small impact of measurement biases on the order of the WMO goals in current inversion systems, the pursuit of measurement uncertainties within the WMO goals is important for several reasons such as future model developments, which may decrease model errors and thus increase the relevance of observation biases (Masarie et al., 2011).

We are not aware of similar bias impact studies for methane. Given the similarity of the corrected biases of $\mathrm{CO}_{2}$ and $\mathrm{CH}_{4}$ with respect to the WMO goals, we expect similarly small impacts for $\mathrm{CH}_{4}$ as for $\mathrm{CO}_{2}$. 
Atmos. Meas. Tech. Discuss., https://doi.org/10.5194/amt-2017-174

Manuscript under review for journal Atmos. Meas. Tech.

Discussion started: 7 June 2017

(c) Author(s) 2017. CC BY 3.0 License.

\section{Atmospheric \\ Measurement Techniques \\ Discussions}

(c) (i)

\section{Conclusions}

We reported previously undocumented biases of $\mathrm{CO}_{2}$ and $\mathrm{CH}_{4}$ measurements obtained with Picarro GHG analyzers in humid air. The biases are due to a sensitivity of the pressure in the measurement cavity to water vapor. We speculate that the underlying physical mechanism is adsorption of water molecules on the piezoresistive pressure sensor in the cavity that is

5 used to keep the pressure constant. The pressure changes affect the water dependency of the $\mathrm{CO}_{2}$ and $\mathrm{CH}_{4}$ measurements. The most important feature of the effect is a transition of the rate of cavity pressure change with respect to water vapor below $0.2 \% \mathrm{H}_{2} \mathrm{O}$. This pressure bend propagates into the $\mathrm{CO}_{2}$ and $\mathrm{CH}_{4}$ measurements and is not modeled well by the traditional parabolic water correction function commonly used for Picarro GHG analyzers, causing water-dependent bias.

To correct for the pressure effect, we proposed an empirical expansion of the traditional water correction. The improved function eliminated the visible systematic offsets in the dry air mole fractions of $\mathrm{CO}_{2}$ and $\mathrm{CH}_{4}$ in our water correction experiments. We observed the bias caused by using the traditional parabolic water correction function to be largest in the range $0.05 \%<\mathrm{H}_{2} \mathrm{O}<0.5 \%$. The largest biases were $0.037 \mathrm{ppm} \mathrm{CO}_{2}$ (corresponding to $0.010 \%$ of the dry air mole fraction) and $0.85 \mathrm{ppb} \mathrm{CH}_{4}(0.046 \%$ of the dry air mole fraction), which are $40 \%$ of the WMO inter-laboratory compatibility goals $\left(80 \%\right.$ for $\mathrm{CO}_{2}$ in the southern hemisphere). Maximum relative biases between dry air mole fractions

15 derived using the traditional model were $0.052 \mathrm{ppm} \mathrm{CO}_{2}$ and $1.2 \mathrm{ppb} \mathrm{CH}_{4}$.

Our experimental results were more robust for $\mathrm{CH}_{4}$ than for $\mathrm{CO}_{2}$ in that the $\mathrm{CH}_{4}$ data were more consistent with the pressure data. Although the reason behind this is not entirely clear, we speculate that it was due to experimental limitations caused by the higher solubility of $\mathrm{CO}_{2}$ in water.

The magnitude of the effect differed between instruments and ranged from being negligible to the values reported above.

Possible changes in the pressure effect over time were not investigated.

Although the functional form was consistent across instruments, coefficients have to be determined for each analyzer individually, since we found differences in the magnitude of the effect. It may be possible to use the average pressure bend position found in our experiments for the correction function of other Picarro GHG analyzers, should existing water correction data not suffice to constrain it. We introduced a method to investigate whether this approach may introduce an error larger than the bias of the traditional water correction function.

To obtain coefficients for the improved water correction function, no pressure data are necessary. Instead, coefficients should be determined directly from $\mathrm{CO}_{2}$ and $\mathrm{CH}_{4}$ data from a water correction experiment. We recommend considering using the pressure bend position derived from $\mathrm{CH}_{4}$ data for $\mathrm{CO}_{2}$ in case of discrepancies, because the $\mathrm{CH}_{4}$ data appeared more consistent with the pressure data in our experiments. Water correction experiments must be designed in a way that allows holding the water vapor mole fraction constant at a defined level to obtain a data point, thus allowing pressure equilibration. During the commonly used droplet experiments, water vapor content in the sample air typically varies quickly around the pressure bend position. This causes a systematic overestimation with large uncertainties of the pressure effect. Therefore, the droplet method is not suitable for obtaining coefficients for the improved water correction function. This 
Atmos. Meas. Tech. Discuss., https://doi.org/10.5194/amt-2017-174

Manuscript under review for journal Atmos. Meas. Tech.

Discussion started: 7 June 2017

(c) Author(s) 2017. CC BY 3.0 License.

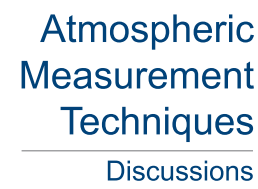

observation further implies that calibrations of Picarro GHG analyzers using dry air must be long enough to allow pressure equilibration (see Sect. 4.6 about the calibration time).

Our work revealed water-dependent biases in the measurements of dry air mole fractions of $\mathrm{CO}_{2}$ and $\mathrm{CH}_{4}$ in humid air obtained using the traditional parabolic water correction function for Picarro GHG analyzers. The biases can reach

5 considerable portions of the WMO inter-laboratory compatibility goals. We provided a way for eliminating the biases with an improved water correction function.

\section{Acknowledgements}

This work was supported by the Max-Planck Society, the European Commission (PAGE21 project, FP7-ENV-2011, grant agreement No. 282700, and PerCCOM project, FP7-PEOPLE-2012-CIG, grant agreement No. PCIG12-GA-201-333796), the German Ministry of Education and Research (CarboPerm-Project, BMBF grant No. 03G0836G), the AXA Research Fund (PDOC_2012_W2 campaign, ARF fellowship M. Göckede), and the European Science Foundation (TTorch Research Networking Programme, Short Visit Grant F. Reum). We thank Stephan Baum, Dietrich Feist and Steffen Knabe (MPIBGC) for help with the experiments. We thank David Hutcherson (Amphenol Thermometrics (UK) Ltd) for clarifications regarding the piezoresisitive pressure measurement technique and Andrew Durso (MPI-BGC) for proofreading the manuscript.

\section{References}

Chen, H., Winderlich, J., Gerbig, C., Hoefer, A., Rella, C. W., Crosson, E. R., Van Pelt, A. D., Steinbach, J., Kolle, O., Beck, V., Daube, B. C., Gottlieb, E. W., Chow, V. Y., Santoni, G. W. and Wofsy, S. C.: High-accuracy continuous airborne measurements of greenhouse gases $\left(\mathrm{CO}_{2}\right.$ and $\left.\mathrm{CH}_{4}\right)$ using the cavity ring-down spectroscopy (CRDS) technique, Atmos. Meas. Tech., 3(2), 375-386, doi:10.5194/amt-3-375-2010, 2010.

Crosson, E. R.: A cavity ring-down analyzer for measuring atmospheric levels of methane, carbon dioxide, and water vapor, Appl. Phys. B Lasers Opt., 92, 403-408, doi:10.1007/s00340-008-3135-y, 2008.

Kirschke, S., Bousquet, P., Ciais, P., Saunois, M., Canadell, J. G., Dlugokencky, E. J., Bergamaschi, P., Bergmann, D., Blake, D. R., Bruhwiler, L., Cameron-Smith, P., Castaldi, S., Chevallier, F., Feng, L., Fraser, A., Heimann, M., Hodson, E. L., Houweling, S., Josse, B., Fraser, P. J., Krummel, P. B., Lamarque, J.-F., Langenfelds, R. L., Le Quéré, C., Naik, V., O’Doherty, S., Palmer, P. I., Pison, I., Plummer, D., Poulter, B., Prinn, R. G., Rigby, M., Ringeval, B., Santini, M., Schmidt, M., Shindell, D. T., Simpson, I. J., Spahni, R., Steele, L. P., Strode, S. A., Sudo, K., Szopa, S., van der Werf, G. R., Voulgarakis, A., van Weele, M., Weiss, R. F., Williams, J. E. and Zeng, G.: Three decades of global methane sources and sinks, Nat. Geosci., 6(10), 813-823, doi:10.1038/ngeo1955, 2013.

Masarie, K. A., Pétron, G., Andrews, A., Bruhwiler, L., Conway, T. J., Jacobson, A. R., Miller, J. B., Tans, P. P., Worthy, D. 
Atmos. Meas. Tech. Discuss., https://doi.org/10.5194/amt-2017-174

Manuscript under review for journal Atmos. Meas. Tech.

Discussion started: 7 June 2017

(c) Author(s) 2017. CC BY 3.0 License.

\section{Atmospheric \\ Measurement \\ Techniques \\ Discussions}

E. and Peters, W.: Impact of $\mathrm{CO}_{2}$ measurement bias on CarbonTracker surface flux estimates, J. Geophys. Res. Atmos., 116(17), 1-13, doi:10.1029/2011JD016270, 2011.

McGuire, A. D., Christensen, T. R., Hayes, D., Heroult, A., Euskirchen, E., Kimball, J. S., Koven, C., Lafleur, P., Miller, P. A., Oechel, W. C., Peylin, P., Williams, M. and Yi, Y.: An assessment of the carbon balance of Arctic tundra: comparisons

5 among observations, process models, and atmospheric inversions, Biogeosciences, 9(8), 3185-3204, doi:10.5194/bg-9-31852012, 2012.

Nara, H., Tanimoto, H., Tohjima, Y., Mukai, H., Nojiri, Y., Katsumata, K. and Rella, C. W.: Effect of air composition (N2, $\mathrm{O} 2$, $\mathrm{Ar}$, and $\mathrm{H} 2 \mathrm{O}$ ) on $\mathrm{CO} 2$ and $\mathrm{CH} 4$ measurement by wavelength-scanned cavity ring-down spectroscopy: Calibration and measurement strategy, Atmos. Meas. Tech., 5(11), 2689-2701, doi:10.5194/amt-5-2689-2012, 2012.

10 Peters, W., Krol, M. C., van der Werf, G. R., Houweling, S., Jones, C. D., Hughes, J., Schaefer, K., Masarie, K. A., Jacobson, A. R., Miller, J. B., Cho, C. H., Ramonet, M., Schmidt, M., Ciattaglia, L., Apadula, F., Heltai, D., Meinhardt, F., di Sarra, A. G., Piacentino, S., Sferlazzo, D., Aalto, T., Hatakka, J., Ström, J., Haszpra, L., Meijer, H. A. J., van Der Laan, S., Neubert, R. E. M., Jordan, A., Rodó, X., Morguí, J. A., Vermeulen, A. T., Popa, E., Rozanski, K., Zimnoch, M., Manning, A. C., Leuenberger, M., Uglietti, C., Dolman, A. J., Ciais, P., Heimann, M. and Tans, P.: Seven years of recent European net 15 terrestrial carbon dioxide exchange constrained by atmospheric observations, Glob. Chang. Biol., 16(4), 1317-1337, doi:10.1111/j.1365-2486.2009.02078.x, 2010.

Rella, C. W., Chen, H., Andrews, A. E., Filges, A., Gerbig, C., Hatakka, J., Karion, A., Miles, N. L., Richardson, S. J., Steinbacher, M., Sweeney, C., Wastine, B. and Zellweger, C.: High accuracy measurements of dry mole fractions of carbon dioxide and methane in humid air, Atmos. Meas. Tech., 6(3), 837-860, doi:10.5194/amt-6-837-2013, 2013.

Rödenbeck, C., Conway, T. J. and Langenfelds, R. L.: The effect of systematic measurement errors on atmospheric $\mathrm{CO}_{2}$ inversions: a quantitative assessment, Atmos. Chem. Phys., 6(6), 149-161, doi:10.5194/acp-6-149-2006, 2006.

Winderlich, J., Chen, H., Gerbig, C., Seifert, T., Kolle, O., Lavrič, J. V., Kaiser, C., Höfer, A. and Heimann, M.: Continuous low-maintenance $\mathrm{CO}_{2} / \mathrm{CH}_{4} / \mathrm{H}_{2} \mathrm{O}$ measurements at the Zotino Tall Tower Observatory (ZOTTO) in Central Siberia, Atmos. Meas. Tech., 3(4), 1113-1128, doi:10.5194/amt-3-1113-2010, 2010.

WMO: 18th WMO/IAEA Meeting on Carbon Dioxide, Other Greenhouse Gases and Related Tracers Measurement Techniques (GGMT-2015). [online] Available from: https://library.wmo.int/opac/doc_num.php?explnum_id=3074, 2016. 
Atmos. Meas. Tech. Discuss., https://doi.org/10.5194/amt-2017-174

Atmospheric

Manuscript under review for journal Atmos. Meas. Tech.

Discussion started: 7 June 2017

(c) Author(s) 2017. CC BY 3.0 License.

Discussions

(c) (1)

Table 1: Overview of experiments.

\begin{tabular}{|l|l|l|l|l|l|l|}
\hline Label & Name & Model & Type & $\begin{array}{l}\text { Droplet } \\
\text { experiment }\end{array}$ & $\begin{array}{l}\text { Gas washing bottle } \\
\text { experiment }\end{array}$ & $\begin{array}{l}\text { External pressure } \\
\text { measurement }\end{array}$ \\
\hline$\# 1$ & CFKBDS2004 & G2401-m & Flight-ready & Yes & Yes & Yes \\
\hline$\# 2$ & CFKADS2199 & G2401 & Ground & No & Yes & Yes \\
\hline$\# 3$ & CFKBDS2108 & G2401-m & Flight-ready & No & Yes & Yes \\
\hline$\# 4$ & CFKBDS2003 & G2401-mc & Flight-ready & Yes & Yes & No \\
\hline$\# 5$ & CFADS2347 & G2301 & Ground & Yes & Yes & No \\
\hline
\end{tabular}

10 
Atmos. Meas. Tech. Discuss., https://doi.org/10.5194/amt-2017-174

Manuscript under review for journal Atmos. Meas. Tech.

Discussion started: 7 June 2017

(c) Author(s) 2017. CC BY 3.0 License.

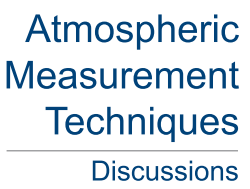

(c) (1)

Table 2: Relationships between external pressure measurement, $\mathrm{CO}_{2}$ and $\mathrm{CH}_{4}$, and internal cavity pressure expressed as slopes (estimate and standard error) with respect to the external pressure measurement. Values shown here were derived for Picarro \#3

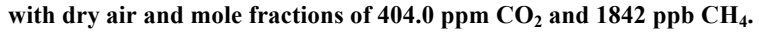

\begin{tabular}{|l|l|}
\hline Cavity pressure & $(1.04 \pm 0.0008)$ Torr Torr \\
\hline $\mathrm{CO}_{2}$ & $(0.502 \pm 0.0006)$ ppm Torr $^{-1}$ \\
\hline $\mathrm{CH}_{4}$ & $(8.25 \pm 0.006)$ ppb Torr $^{-1}$ \\
\hline
\end{tabular}

5 
Atmos. Meas. Tech. Discuss., https://doi.org/10.5194/amt-2017-174

Manuscript under review for journal Atmos. Meas. Tech.

Discussion started: 7 June 2017

(c) Author(s) 2017. CC BY 3.0 License.

(c) (1)
Atmospheric Measurement Techniques Discussions

Table 3: Fit coefficients (estimate and standard error) from Eq. (3) for three Picarro GHG analyzers

\begin{tabular}{|l|l|l|l|}
\hline Picarro analyzer & $s\left[\right.$ Torr $\left.\left(\% \mathrm{H}_{2} \mathrm{O}\right)^{-1}\right]$ & $h_{p}\left[\% \mathrm{H}_{2} \mathrm{O}\right]$ & $d_{p}$ [Torr] \\
\hline$\# 1$ & $-0.17 \pm 0.012$ & $0.066 \pm 0.0092$ & $0.18 \pm 0.012$ \\
\hline$\# 2$ & $-0.14 \pm 0.0042$ & $0.076 \pm 0.009$ & $0.14 \pm 0.0065$ \\
\hline$\# 3$ & $-0.076 \pm 0.0047$ & $0.095 \pm 0.011$ & $0.21 \pm 0.0092$ \\
\hline
\end{tabular}

5 
Atmos. Meas. Tech. Discuss., https://doi.org/10.5194/amt-2017-174

Manuscript under review for journal Atmos. Meas. Tech.

Discussion started: 7 June 2017

(c) Author(s) 2017. CC BY 3.0 License.

Table 4: Water correction coefficients for Picarro \#5 based on Eq. (5). The parameter $h_{p}$ was taken from Eq. (4). See also Table 5.

\begin{tabular}{|l|l|l|l|}
\hline Species & $a_{c}\left[\left(\% \mathrm{H}_{2} \mathrm{O}\right)^{-1}\right]$ & $b_{c}\left[\left(\% \mathrm{H}_{2} \mathrm{O}\right)^{-2}\right]$ & $d_{c}$ [unitless] \\
\hline $\mathrm{CO}_{2}$ & $(-1.539 \pm 0.005) \times 10^{-2}$ & $(3.4 \pm 1.6) \times 10^{-5}$ & $(1.6 \pm 0.3) \times 10^{-4}$ \\
\hline $\mathrm{CH}_{4}$ & $(-1.30 \pm 0.02) \times 10^{-2}$ & $(1.9 \pm 5.2) \times 10^{-5}$ & $(6.6 \pm 1.0) \times 10^{-4}$ \\
\hline
\end{tabular}

5 
Atmos. Meas. Tech. Discuss., https://doi.org/10.5194/amt-2017-174

Manuscript under review for journal Atmos. Meas. Tech.

Discussion started: 7 June 2017

(c) Author(s) 2017. CC BY 3.0 License.

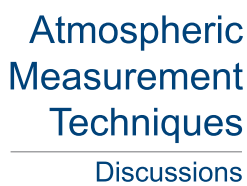

(c) (1)

Table 5: Same as Table 4, but for fits using $\mathrm{H}_{2} \mathrm{O}_{\text {rep }}$ instead of $\mathrm{H}_{2} \mathrm{O}$ for comparability of the coefficients $\boldsymbol{a}_{c}$ and $b_{c}$ to previous studies (Chen et al., 2010; Rella et al., 2013). Dry air mole fractions obtained with either set of coefficients were virtually identical $\left(\Delta \mathrm{CO}_{2}< \pm 0.0008 \mathrm{ppm}\right.$ and $\Delta \mathrm{CH}_{4}< \pm 0.002 \mathrm{ppb}$; results for the coefficients reported in Table 4 are in Fig. 5), and for subsequent analyses the coefficients reported in Table 4 were used.

\begin{tabular}{|l|l|l|l|}
\hline Species & $a_{c}\left[\left(\% \mathrm{H}_{2} \mathrm{O}_{\text {rep }}\right)^{-1}\right]$ & $b_{c}\left[\left(\% \mathrm{H}_{2} \mathrm{O}_{\text {rep }}\right)^{-2}\right]$ & $d_{c}$ [unitless] \\
\hline $\mathrm{CO}_{2}$ & $(-1.189 \pm 0.004) \times 10^{-2}$ & $(-2.7 \pm 0.1) \times 10^{-4}$ & $(1.5 \pm 0.3) \times 10^{-4}$ \\
\hline $\mathrm{CH}_{4}$ & $(-1.01 \pm 0.01) \times 10^{-2}$ & $(-2.4 \pm 0.4) \times 10^{-4}$ & $(6.6 \pm 1.1) \times 10^{-4}$ \\
\hline
\end{tabular}

5

10 
Atmos. Meas. Tech. Discuss., https://doi.org/10.5194/amt-2017-174

Manuscript under review for journal Atmos. Meas. Tech.

Discussion started: 7 June 2017

(c) Author(s) 2017. CC BY 3.0 License.

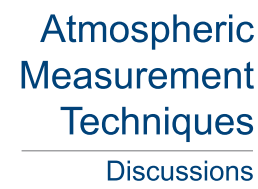

(c) (i)

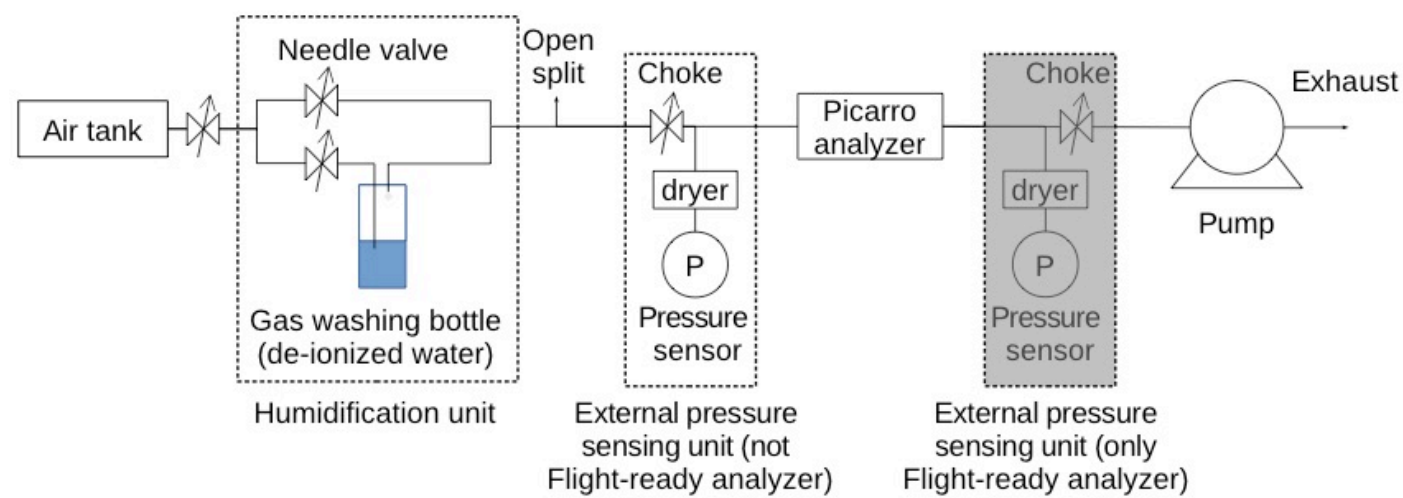

Fig. 1: Experimental setup used for the water correction experiments. For Flight-ready analyzers, the external pressure sensor was installed downstream of the analyzer, instead of upstream. For droplet experiments, the humidification unit was replaced by a tee piece. 
Atmos. Meas. Tech. Discuss., https://doi.org/10.5194/amt-2017-174

Manuscript under review for journal Atmos. Meas. Tech.

Discussion started: 7 June 2017

(c) Author(s) 2017. CC BY 3.0 License.

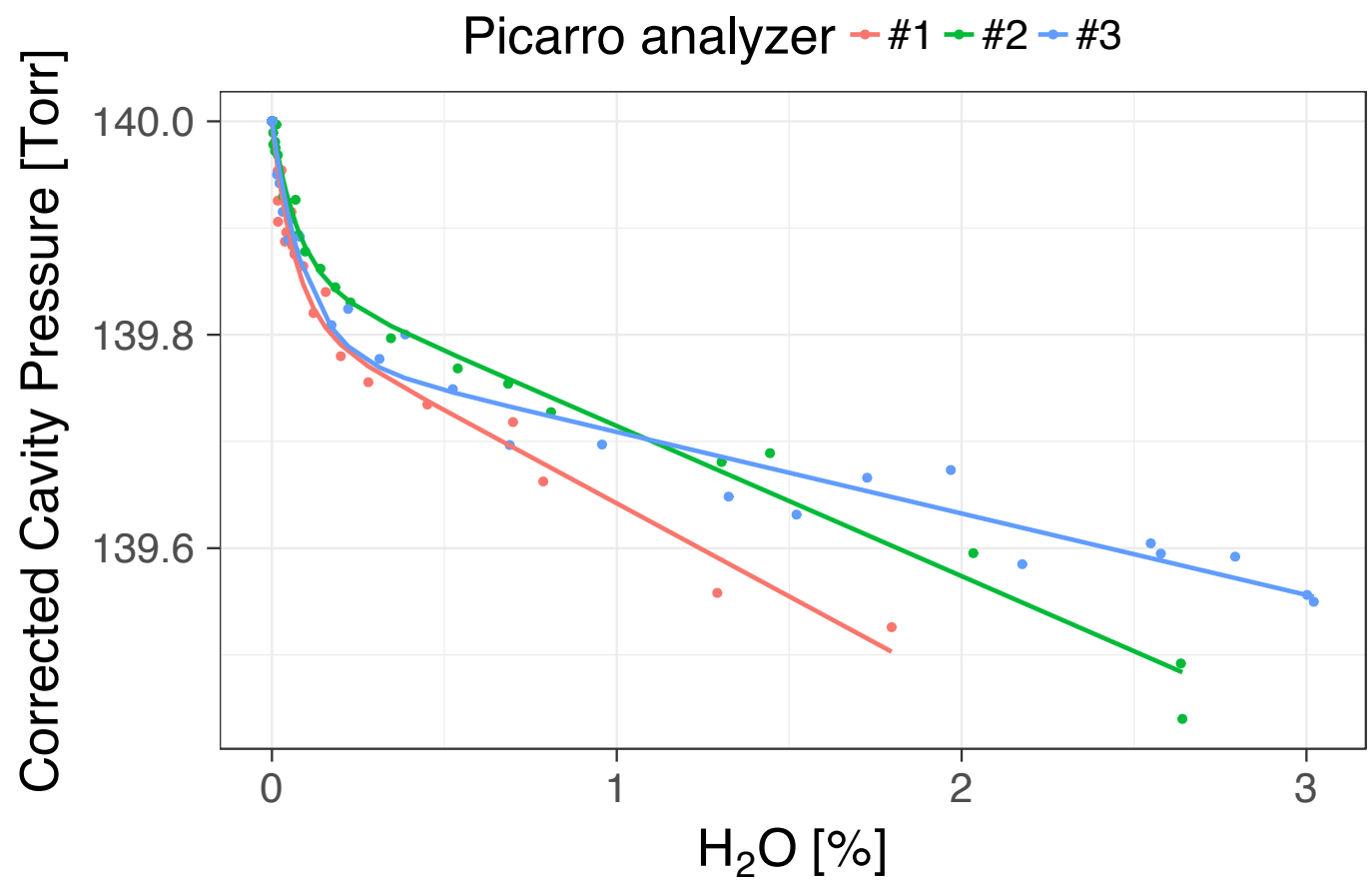

Fig. 2: Cavity pressure as a function of water vapor for three Picarro GHG analyzers. The lines are the fits to Eq. (3). 
Atmos. Meas. Tech. Discuss., https://doi.org/10.5194/amt-2017-174

Manuscript under review for journal Atmos. Meas. Tech.

Discussion started: 7 June 2017

(c) Author(s) 2017. CC BY 3.0 License.

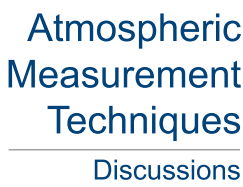

(c) (1)
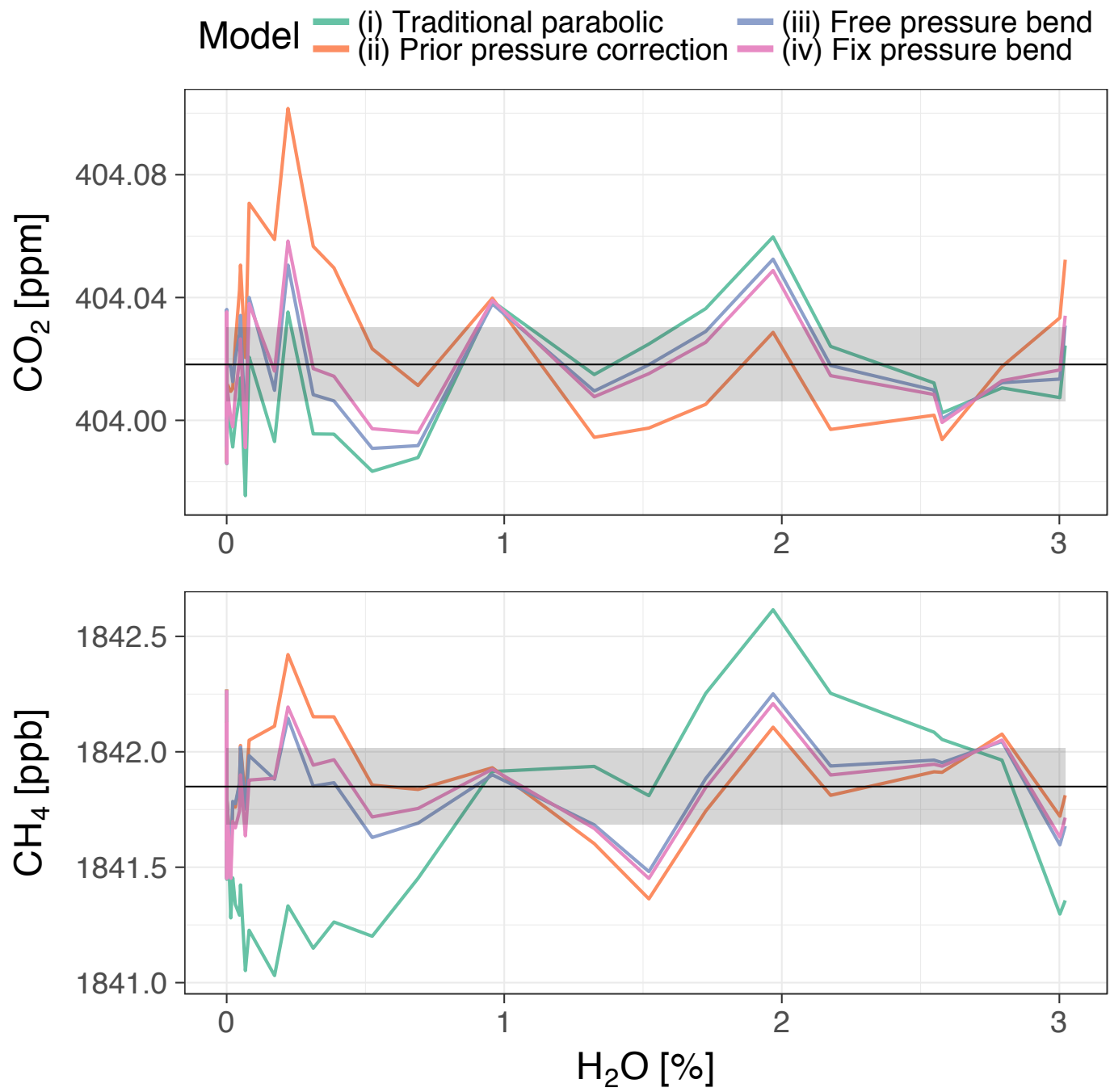

Fig. 3: $\mathrm{CO}_{2}$ and $\mathrm{CH}_{4}$ dry air mole fractions for Picarro \#3 based on the four water correction functions described in the text. The grey bar denotes one standard deviation of the trace gas during the dry air measurements that were obtained between different water vapor levels. 
Atmos. Meas. Tech. Discuss., https://doi.org/10.5194/amt-2017-174

Manuscript under review for journal Atmos. Meas. Tech.

Discussion started: 7 June 2017

(C) Author(s) 2017. CC BY 3.0 License.
Atmospheric Measurement

Techniques

Discussions
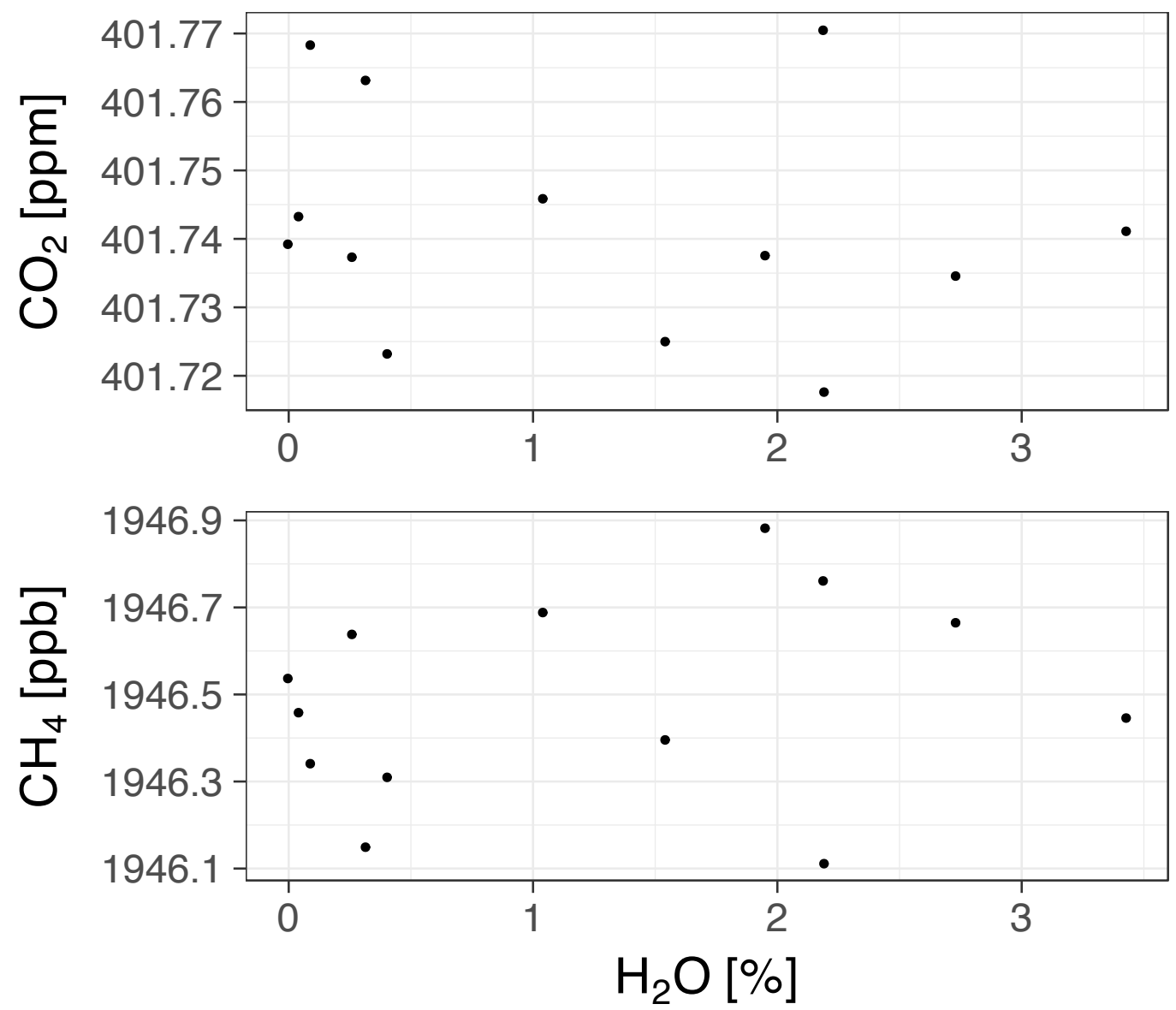

Fig. 4: Dry air mole fractions of $\mathrm{CO}_{2}$ and $\mathrm{CH}_{4}$ for a gas washing bottle experiment with Picarro \#4 based on the traditional parabolic water correction function. No systematic biases are obvious. 
Atmos. Meas. Tech. Discuss., https://doi.org/10.5194/amt-2017-174

Manuscript under review for journal Atmos. Meas. Tech.

Discussion started: 7 June 2017

(c) Author(s) 2017. CC BY 3.0 License.

Model - (i) Traditional parabolic - (iv) Fix pressure bend
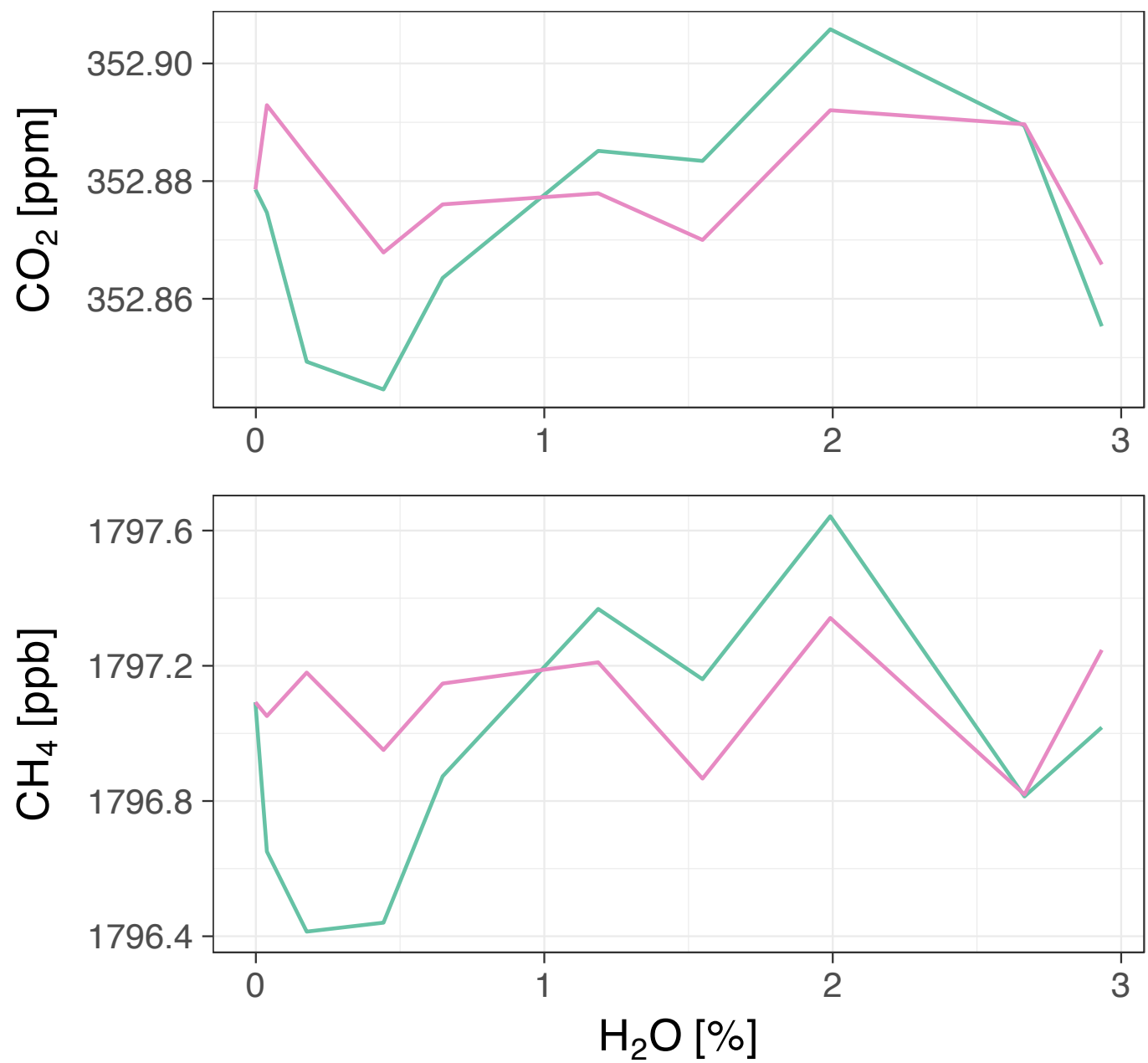

Fig. 5: Dry air mole fractions of $\mathrm{CO}_{2}$ and $\mathrm{CH}_{4}$ for Picarro \#5 from a gas washing bottle experiment. Shown here are results for the traditional parabolic water correction function, and the improved water correction function using $h_{p}$ from Eq. (4) (model (iv); see also Sect. 3.3). 
Atmos. Meas. Tech. Discuss., https://doi.org/10.5194/amt-2017-174

Manuscript under review for journal Atmos. Meas. Tech.

Discussion started: 7 June 2017

Atmospheric

Measurement

Techniques

(c) Author(s) 2017. CC BY 3.0 License.

Discussions

(c) (i)
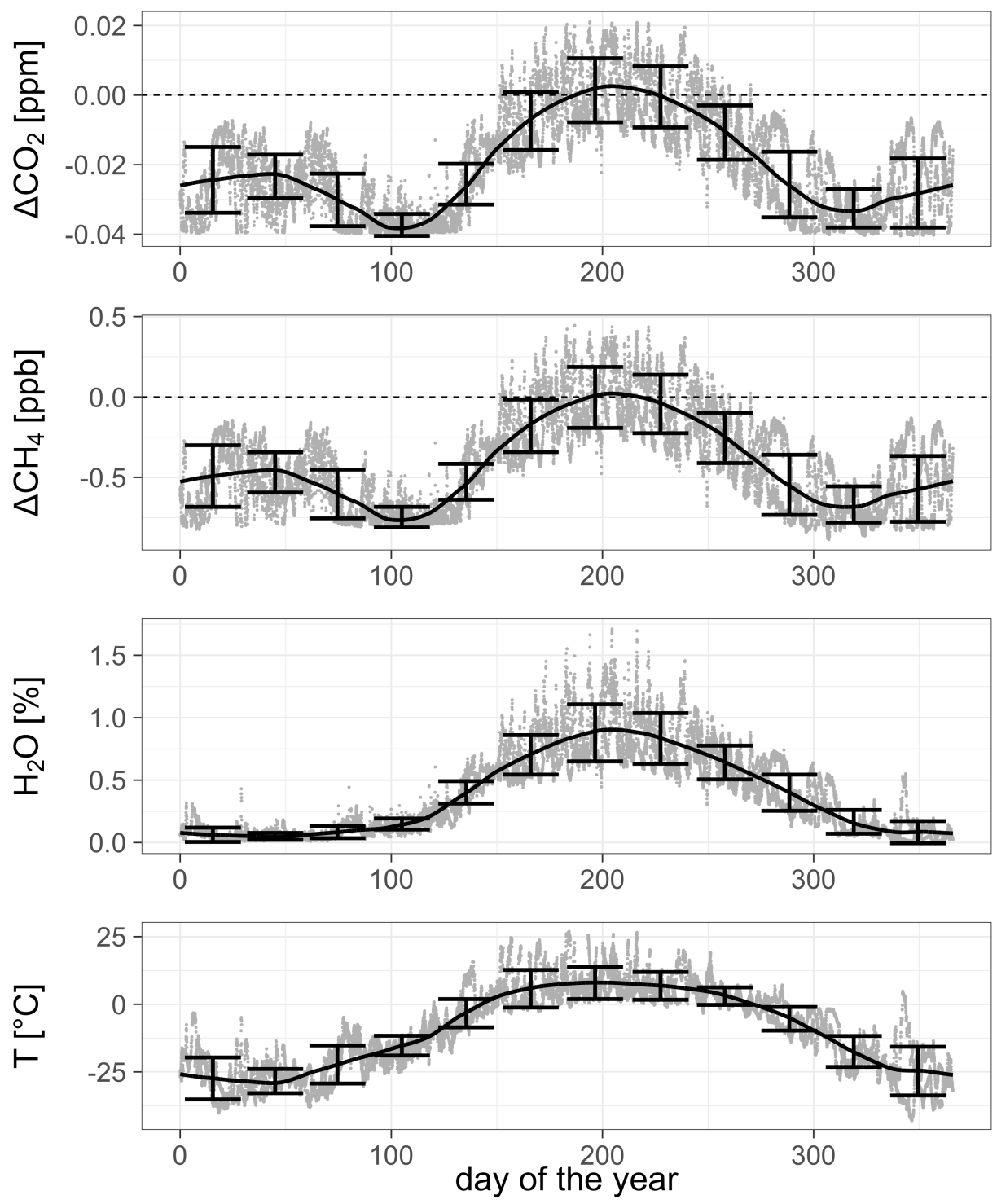

Fig. 6: Difference between the traditional and the improved water correction of Ambarchik data for 2015 and 2016 . Dots: hourly averages of the air inlet at $27 \mathrm{~m}$, line: smoothed data, error bars: monthly averages and standard deviation. Water vapor content and ambient temperature are plotted for reference. 
Atmos. Meas. Tech. Discuss., https://doi.org/10.5194/amt-2017-174

Manuscript under review for journal Atmos. Meas. Tech.

Discussion started: 7 June 2017

(c) Author(s) 2017. CC BY 3.0 License.

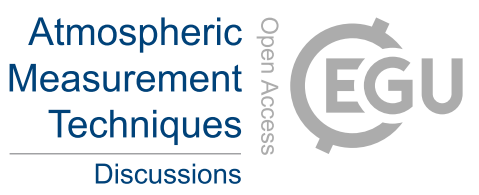

(c)

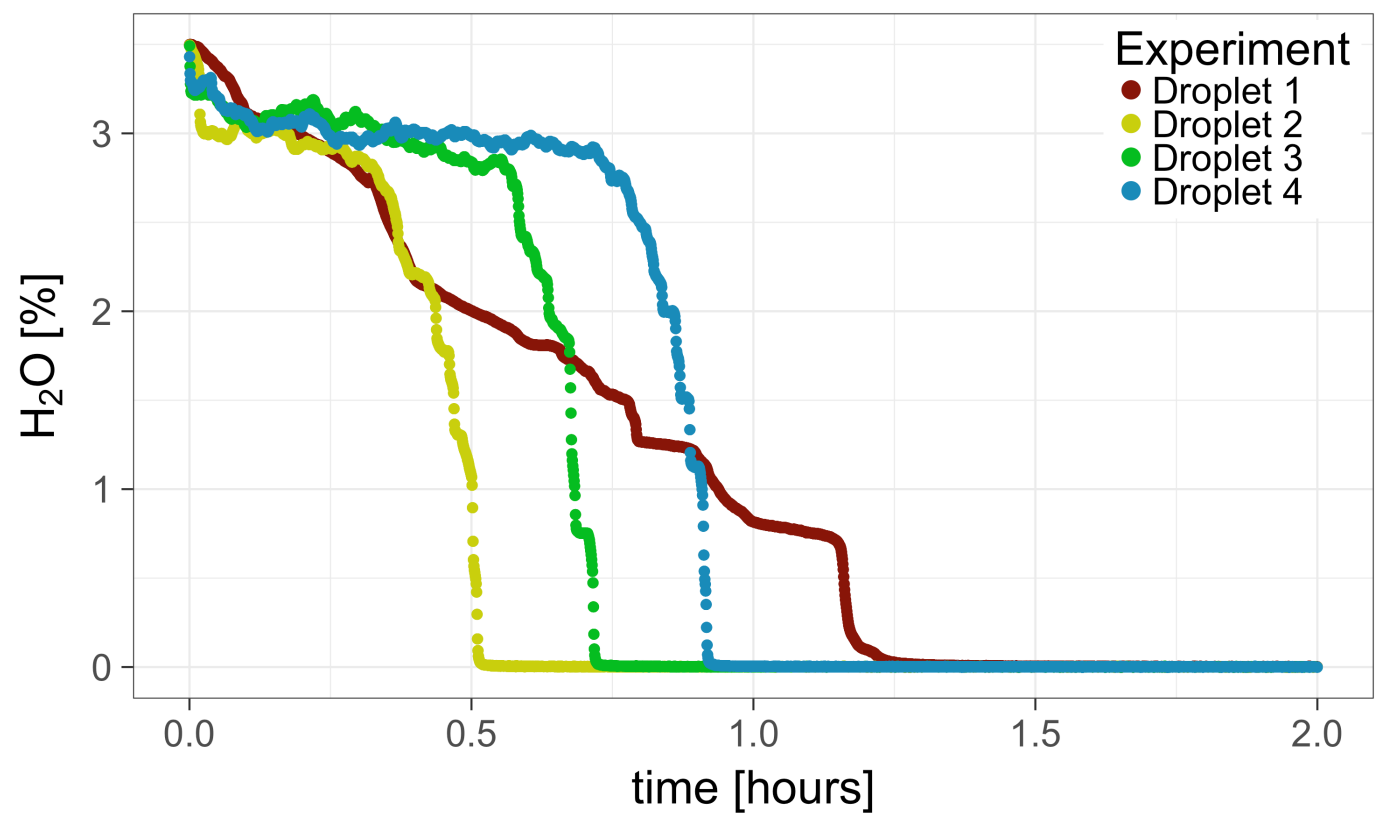

Fig. 7: Temporal progression of water vapor content during the droplet experiments after the drop below $3.5 \%$ $\mathrm{H}_{2} \mathrm{O}$. To illustrate the effect of fast water vapor changes on pressure, fast water vapor variations have not been filtered out for this plot. 
Atmos. Meas. Tech. Discuss., https://doi.org/10.5194/amt-2017-174

Manuscript under review for journal Atmos. Meas. Tech.

Discussion started: 7 June 2017

(c) Author(s) 2017. CC BY 3.0 License.

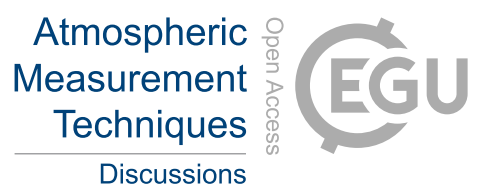

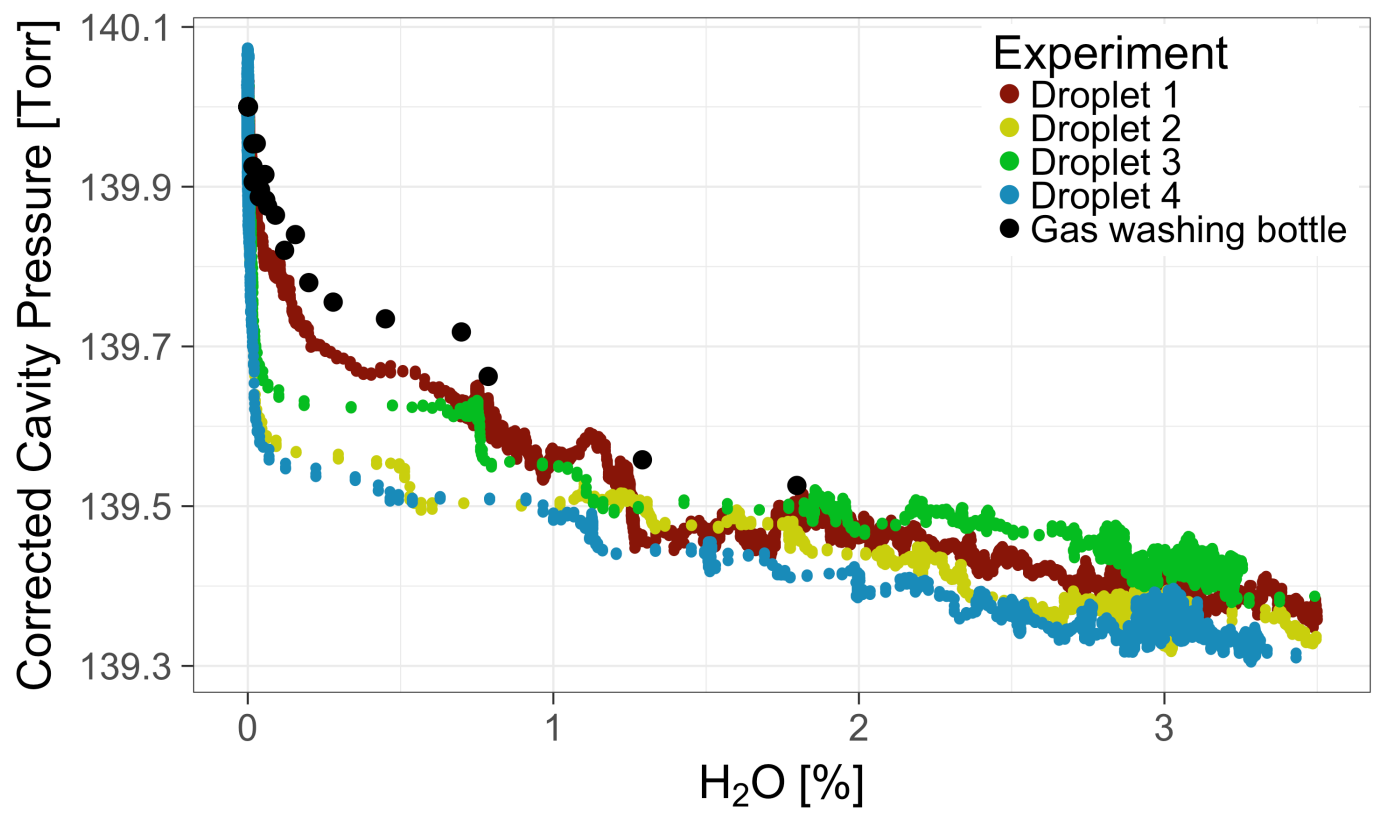

Fig. 8: Cavity pressure during four droplet experiments and one gas washing bottle experiment with Picarro \#1. To illustrate the effect of fast water vapor changes on pressure, fast water vapor variations have not been filtered out for this plot.

5 
Atmos. Meas. Tech. Discuss., https://doi.org/10.5194/amt-2017-174

Manuscript under review for journal Atmos. Meas. Tech.

Discussion started: 7 June 2017

(C) Author(s) 2017. CC BY 3.0 License.

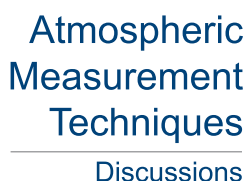

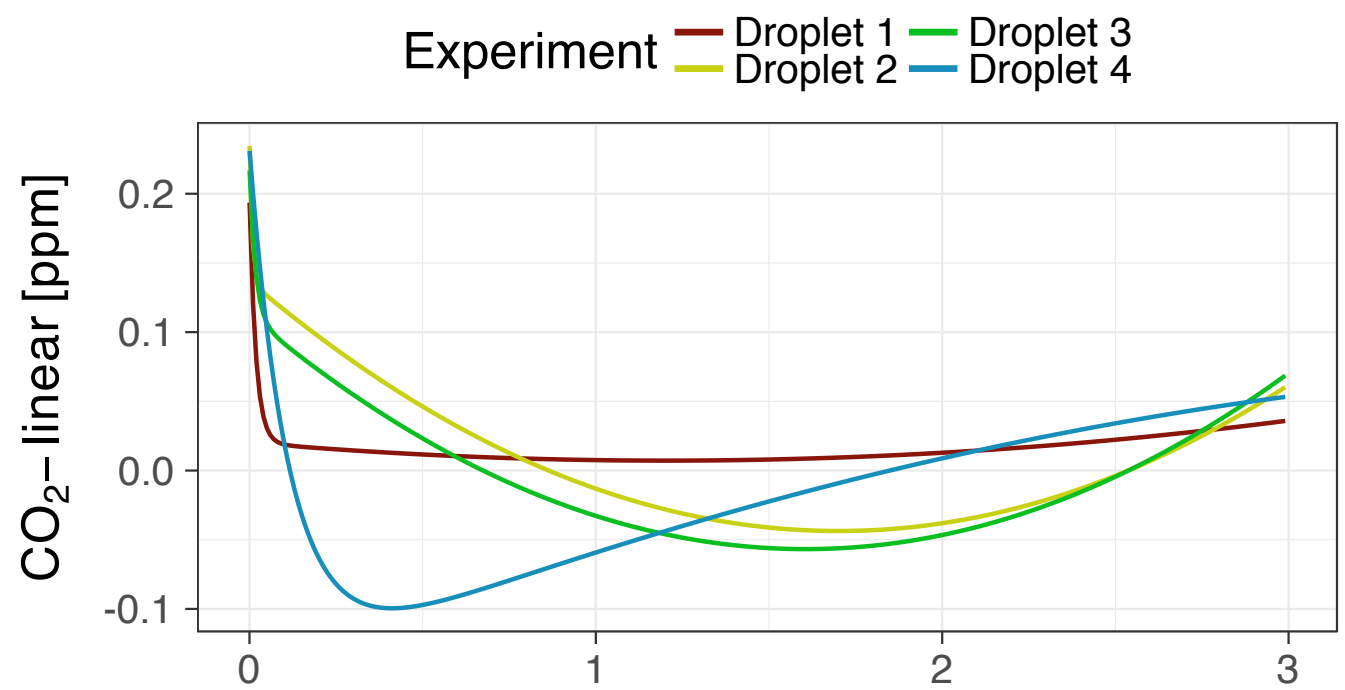

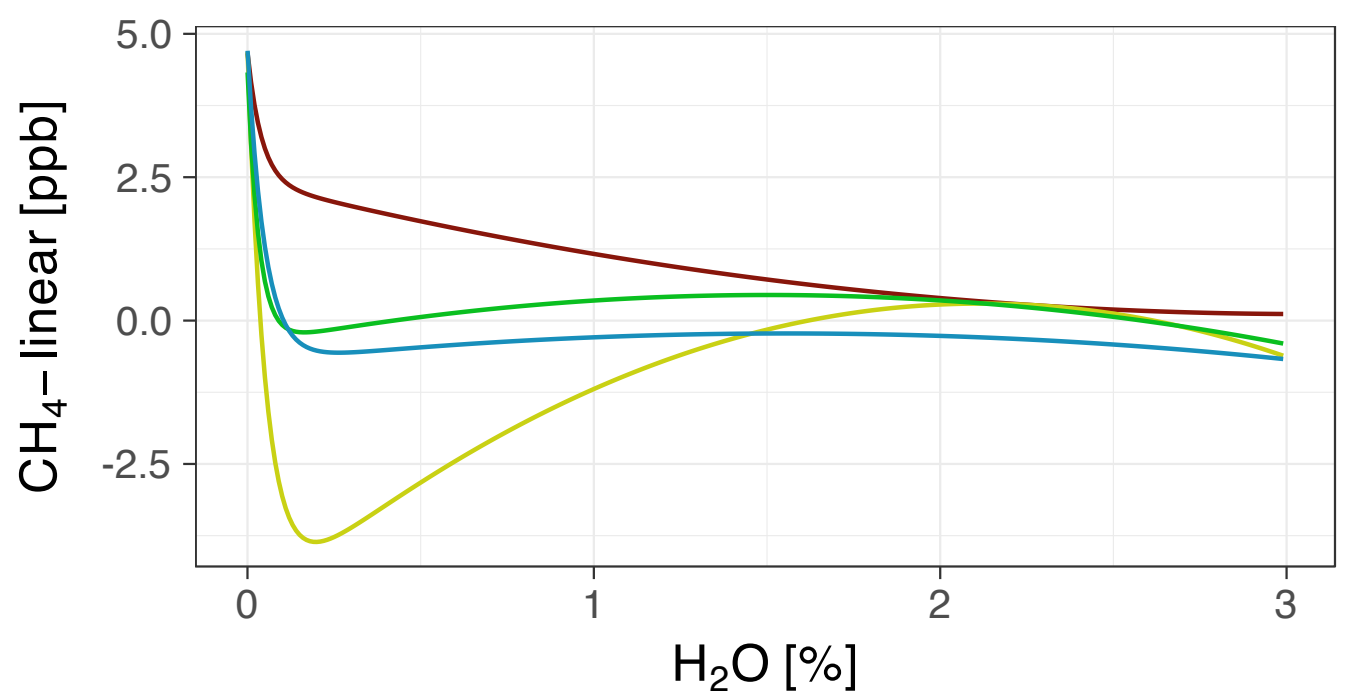

Fig. 9: Fit functions to data from four droplet experiments with Picarro \#1. To emphasize differences, a common linear component has been subtracted from the fit functions. In these fits, the pressure bend position $h_{p}$ has been fit to the trace gas data. 